\title{
A comparison of two chemistry and aerosol schemes on the regional scale and the resulting impact on radiative properties and liquid- and ice-phase aerosol-cloud interactions
}

\author{
Franziska Glassmeier ${ }^{1, \mathrm{a}, \mathrm{b}}$, Anna Possner ${ }^{1, \mathrm{c}}$, Bernhard Vogel ${ }^{2}$, Heike Vogel $^{2}$, and Ulrike Lohmann ${ }^{1}$ \\ ${ }^{1}$ Institute for Atmospheric and Climate Science, ETH Zurich, Zurich, Switzerland \\ ${ }^{2}$ Institut für Meteorologie und Klimaforschung, Karlsruhe Institute of Technology (KIT), Karlsruhe, Germany \\ ${ }^{a}$ currently at: National Research Council, Washington DC, USA \\ b currently at: Chemical Sciences Division, NOAA Earth System Research Laboratory, Boulder, USA \\ ${ }^{\mathrm{c}}$ currently at: Department of Global Ecology, Carnegie Institution for Science, Stanford, USA
}

Correspondence to: Franziska Glassmeier (franziska.glassmeier@noaa.gov)

Received: 3 December 2016 - Discussion started: 24 February 2017

Revised: 5 June 2017 - Accepted: 9 June 2017 - Published: 17 July 2017

\begin{abstract}
The complexity of atmospheric aerosol causes large uncertainties in its parameterization in atmospheric models. In a process-based comparison of two aerosol and chemistry schemes within the regional atmospheric modeling framework COSMO-ART (Consortium for Small-Scale Modelling, Aersosol and Reactive Trace gases extension), we identify key sensitivities of aerosol parameterizations. We consider the aerosol module MADE (Modal Aerosol Dynamics model for Europe) in combination with full gasphase chemistry and the aerosol module M7 in combination with a constant-oxidant-field-based sulfur cycle. For a Saharan dust outbreak reaching Europe, modeled aerosol populations are more sensitive to structural differences between the schemes, in particular the consideration of aqueousphase sulfate production, the selection of aerosol species and modes, and modal composition, than to parametric choices like modal standard deviation and the parameterization of aerosol dynamics. The same observation applies to aerosol optical depth (AOD) and the concentrations of cloud condensation nuclei $(\mathrm{CCN})$. Differences in the concentrations of ice-nucleating particles (INPs) are masked by uncertainties between two ice-nucleation parameterizations and their coupling to the aerosol scheme. Differences in cloud droplet and ice crystal number concentrations are buffered by cloud microphysics as we show in a susceptibility analysis.
\end{abstract}

\section{Introduction}

Atmospheric aerosol poses the most uncertain factor in quantifying the anthropogenic forcing of the climate system (Myhre et al., 2013). This uncertainty is rooted in the complexity of aerosol characteristics and processes: aerosol particles feature many microscopic degrees of freedom, like their chemical composition, mixing state or shape, and interact with several atmospheric components like atmospheric chemistry, the planetary surface as source of primary emissions, radiation by scattering and absorption, and the hydrological cycle via aerosol-cloud interactions (Lohmann et al., 2016). Given their microscopic scale, all these processes and characteristics have to be parameterized to be represented in atmospheric models.

Approaches to represent aerosol particles in atmospheric models employ discrete (binned) or continuous (modal) distributions of particle sizes (Jacobson, 2005). They consider different selections of chemical species like sea salt, dust, sulfate, nitrate and classes of organics, e.g., soot and primary or secondary organic aerosol, that are grouped in internally and/or externally mixed particle classes. The parameterizations of aerosol microphysical processes like gas-to-particle conversion, coagulation, and dry and wet deposition depend on these structural aerosol characteristics (e.g., Vignati et al., 2004; Vogel et al., 2009).

Modeled aerosol particles can be coupled to an atmospheric host model to different degrees: atmospheric chem- 
istry can be considered from simplified sulfur cycles using climatological oxidant fields (e.g., Zubler et al., 2011) to full chemistry including aqueous-phase reactions (e.g., Knote and Brunner, 2013). Primary aerosol emissions may be prescribed from inventories or modeled online taking into account surface conditions (e.g., Vignati et al., 2004; Vogel et al., 2009). Aerosols can also be coupled to radiation via their absorbing and scattering properties and to cloud formation by their ability to serve as cloud condensation nuclei (CCN) or ice-nucleating particles (INPs) (Lohmann et al., 2016). The latter aerosol-cloud interactions constitute the largest source of uncertainty in anthropogenic aerosol forcing (Myhre et al., 2013). Clearly, the challenge lies in choosing the right degree of complexity for a given task, e.g., air-quality applications or climate projections. An informed choice requires an understanding of key processes and sensitivities of aerosol parameterizations.

While aerosol microphysics take place on the microscale, aerosols can be transported globally (Lohmann et al., 2016). Regional atmospheric models are valuable tools to increase our process understanding because they compromise between process representation that is improved at higher spatial resolutions and larger-scale transport patterns (e.g., Possner et al., 2015; Rieger et al., 2014; Athanasopoulou et al., 2013; Knote and Brunner, 2013; Bangert et al., 2012; Fountoukis et al., 2011; Zubler et al., 2011). Nevertheless, our current understanding of aerosols remains insufficient (Myhre et al., 2013). While for air-quality applications in general and case studies in particular, the uncertainties in aerosol representation can be somewhat controlled by tuning the parameterization to match observations, reducing the uncertainty of climate projections depends on improving our understanding of key sensitivities of aerosol parameterizations (Lee et al., 2016).

Multi-model intercomparisons and sensitivity studies using a single model are complementary approaches to assess uncertainties of aerosol parameterizations: intercomparisons compare different representations of aerosol characterizations, process parameterizations and parameter choices in a statistical fashion. Observed differences are judged in comparison to observational data and can usually not be attributed to specific processes or characteristics and their implementation. The AQMEII (Air Quality Modelling Evaluation International Initiative) is an example of a statistical intercomparison and evaluation of multiple regional aerosol and chemistry transport models and reports large variability between different models that seems related to aerosol deposition but could not be explained at the process level (Solazzo, 2012). On the global scale and with a focus on climate applications, the AeroCom (Aerosol Comparison) multi-model intercomparison initiative likewise reports large model diversity and concludes from observational biases that emissions and gas-to-particle conversion are insufficiently understood (Mann et al., 2014). Differences in model per- formance could not be attributed to specific process parameterizations in most cases, however.

Numerical sensitivity studies test the effect of changing a certain parameter or the description of a specific process or aerosol characteristic on the variables of interest and can help to explain model variability. A sensitivity study of model performance to updated process representations, for example, allows Zhang et al. (2012) to attribute an improvement in modeled aerosol water content in comparison to the AeroCom multi-model mean to a $\kappa$-Köhler approach to water uptake. Lee et al. (2012) assess the parametric uncertainty regarding simulated $\mathrm{CCN}$ concentrations using an emulator technique that reveals the importance of interactions between different parameters and thus highlights the importance of comparing specific sets of parameters and parameterizations rather than varying them one at a time.

This study might be considered a hybrid between the model comparison and sensitivity studies discussed above and naturally takes into account combinations of parameters and parameterization approaches: we will present a detailed comparison of two different modal aerosol schemes, one developed by the climate community and one that emerged from air-quality and weather prediction applications, that are embedded into the same regional atmospheric model. This study intends to highlight key sensitivities to be considered when designing or choosing a modal aerosol scheme. It does not aim to identify the "better" of the two schemes, which will depend on the specific application. Our analysis comprises targeted sensitivity studies that require an adapted setup of the two aerosol schemes as well as a model comparison of both schemes in their default setups. For the latter, we additionally discuss resulting impacts on the radiative aerosol properties and implications for liquid- and ice-phase aerosol-cloud interactions.

The rest of the paper is organized as follows: detailed model descriptions are given in Sect. 2. Section 3 describes the different model setups that our analysis is based on. Section 4 compares an adapted version of both aerosol schemes in a sensitivity study, while Sect. 5 is concerned with the differences between the two schemes in their default setups as well as aerosol optical properties and aerosol-cloud interactions. We summarize and discuss our results in Sect. 6. A list of abbreviations and terms is provided in Appendix A. An earlier version of this paper constitutes a chapter of the doctoral thesis of Franziska Glassmeier (Glassmeier, 2016).

\section{Model descriptions: COSMO-ART and COSMO-ART-M7}

We employ the atmospheric aerosol and chemistry modeling framework COSMO-ART (Vogel et al., 2009), which is based on the regional atmospheric model COSMO (Consortium for Small-Scale Modelling; www.cosmo-model.org). The ART (Aersosol and Reactive Trace gases) extension 


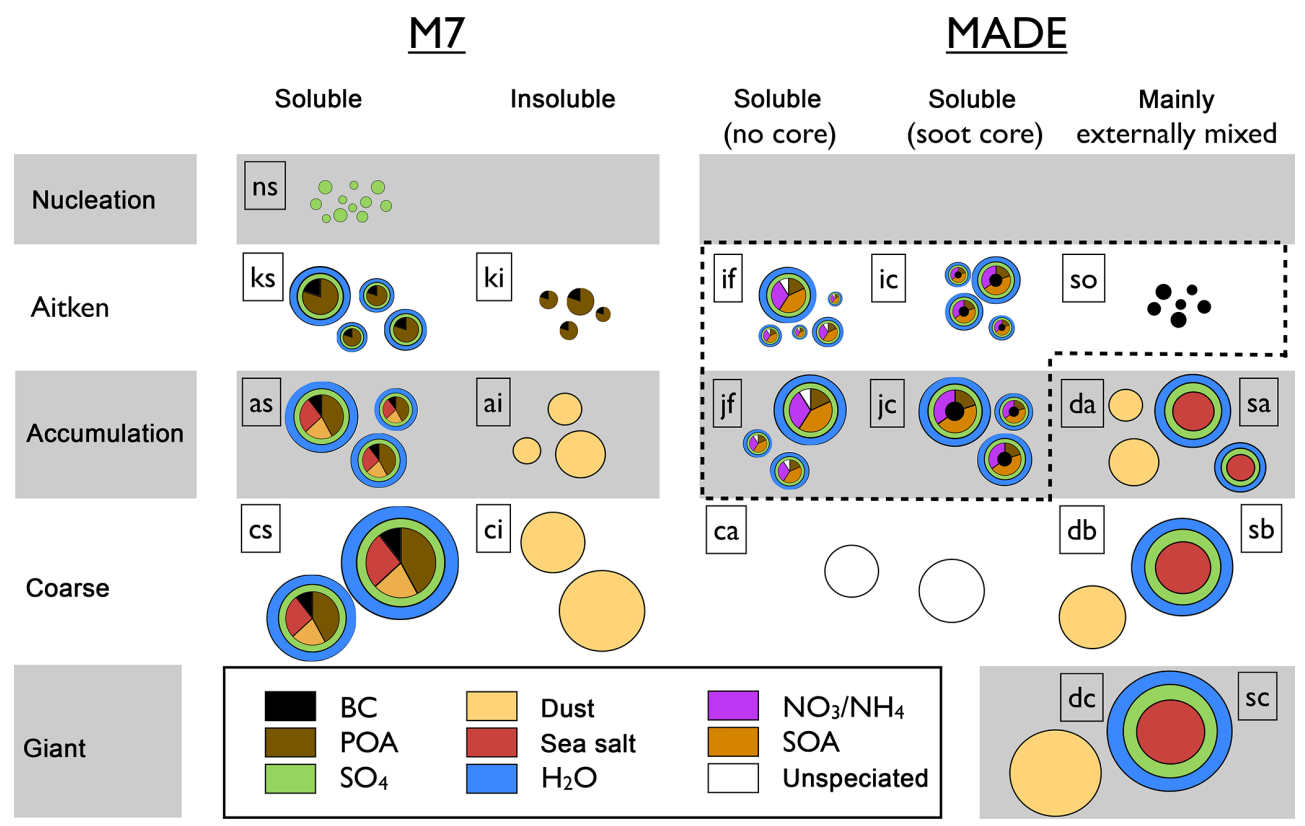

Figure 1. Comparison of chemical composition of aerosol modes for MADE and M7. The dashed line indicates modes that are considered for inter- and intra-modal coagulation in MADE. For M7, all modes participate in coagulation or intra-modal transfer by coagulation. The size and standard deviation of modes can be determined from Table 1 based on the two-letter abbreviations stated at the upper left of each mode (ns: M7 nucleation mode; ks: M7 solute-containing Aitken mode; ki: M7 insoluble Aitken mode; as: M7 solute-containing accumulation mode; ai: M7 insoluble accumulation mode; cs: M7 solute-containing coarse mode; ci: M7 insoluble coarse mode; if: MADE soluble Aitken mode without soot core; ic: MADE soluble Aitken mode with soot core; so: MADE pure soot mode; jf: MADE soluble accumulation mode without soot core; jc: MADE soluble accumulation mode with soot core; ca: MADE unspeciated anthropogenic coarse mode; da: MADE accumulation dust mode; db: MADE coarse dust mode; dc: MADE giant dust mode; sa: MADE accumulation sea salt mode; sb: MADE coarse sea salt mode; sc: MADE giant sea salt mode).

of COSMO features online-coupled gas-phase chemistry and the modal two-moment aerosol scheme MADE (Modal Aerosol Dynamics model for Europe) as well as aerosolradiation and aerosol-cloud interactions. COSMO-ART has a tradition of air-quality modeling and has been extended to investigate the role of interactive aerosol in weather prediction (e.g., Bangert et al., 2012; Rieger et al., 2014).

We compare this standard version of COSMO-ART to a new assembled model version called COSMO-ART-M7. This new version integrates the modal two-moment aerosol module M7 (Vignati et al., 2004; Stier et al., 2005) and the computationally efficient sulfur chemistry of Feichter et al. (1996), as an alternative to the full chemistry and MADE, into the COSMO-ART framework. The efficient chemistry is implemented using the code generator KPP (Damian et al., 2002) that is available within COSMO-ART. The implementation of the aqueous-phase chemistry relies on the reaction rate implementation from GEOS-CHEM (map.nasa.gov/ GEOS_CHEM_f90toHTML/). Our implementation of the Feichter sulfur cycle is coupled to the updated version of the M7 aerosol microphysics as implemented in the global climate model ECHAM-HAM2.2 (Zhang et al., 2012). Primary emissions and dry and wet deposition as well as aerosolcloud interactions from COSMO-ART are adapted to M7 aerosol modes. The implementation of aerosol-optical properties is M7-specific and is described in Zubler et al. (2011).

The M7 module has been developed for climate applications in global models. COSMO-ART-M7 can be considered an updated version of COSMO-M7 (Zubler et al., 2011): next to the current versions of COSMO and M7, COSMO-ARTM7 profits from the state-of-the-art droplet activation and ice-nucleation parameterizations of COSMO-ART. In contrast to COSMO-M7, COSMO-ART-M7 includes aerosolcloud interactions in cirrus clouds. The remainder of this section provides details on the parameterizations and adaptations.

\subsection{Aerosol}

The aerosol module MADE of COSMO-ART represents atmospheric aerosol by 12 coated and uncoated lognormal modes in the Aitken, accumulation, coarse and giant size ranges. For the composition of aerosol particles, 13 chemical species are considered: dust (DU), sea salt (SS), sulfate $\left(\mathrm{SO}_{4}\right)$, nitrate $\left(\mathrm{NO}_{3}\right)$, ammonium $\left(\mathrm{NH}_{4}\right)$, black carbon/soot (BC), primary organic carbon (POA), four volatility classes for secondary organic aerosols (SOA) representative of different SOA species (Athanasopoulou et al., 2013), and un- 
Table 1. Comparison of modal parameters for MADE and M7 modes. Each mode is identified by a two-letter abbreviation (italic font), which allows us to identify its chemical composition in Fig. 1. Modal standard deviation is denoted by $\sigma$. Modal median radii of the number distributions, $r$, refer to initial and emission radii for MADE. In contrast to MADE, M7 features a mode repartitioning ensuring that the radii of M7 modes are restricted to the indicated ranges. Mode reorganization in MADE is limited to ensure that the radii of Aitken modes remain smaller than those of accumulation modes. MADE and M7 modes are grouped to show correspondence.

\begin{tabular}{|c|c|c|c|c|c|c|c|c|c|c|c|c|c|}
\hline Mode & Nucleation & \multicolumn{3}{|c|}{ Aitken } & \multicolumn{4}{|c|}{ Accumulation } & \multicolumn{3}{|c|}{ Coarse } & \multicolumn{2}{|c|}{ Giant } \\
\hline MADE & - & if & $i c$ & so & jf & $j c$ & $s a$ & $d a$ & $\mathrm{ca}$ & $s b$ & $d b$ & $s c$ & $d c$ \\
\hline$\sigma$ & - & 1.7 & 2.0 & 1.4 & 1.7 & 2 & 1.9 & 1.7 & 2.5 & 2 & 1.6 & 1.7 & 1.5 \\
\hline$r / \mu \mathrm{m}$ & - & 0.005 & 0.04 & 0.04 & 0.035 & 0.04 & 0.1 & 0.32 & 0.5 & 1.0 & 1.7 & 6.0 & 4.3 \\
\hline M7 & $n s$ & \multicolumn{2}{|c|}{$k s$} & $k i$ & \multicolumn{3}{|c|}{ as } & $a i$ & \multicolumn{2}{|c|}{$c s$} & $c i$ & \multicolumn{2}{|c|}{ - } \\
\hline$\sigma$ & 1.59 & & & 1.59 & & 1.59 & & 1.59 & & 0 & 2.0 & \multirow{2}{*}{\multicolumn{2}{|c|}{ - }} \\
\hline$r / \mu \mathrm{m}$ & $<0.005$ & \multicolumn{3}{|c|}{$0.005-0.05$} & \multicolumn{3}{|c|}{$0.05-0.5$} & & \multicolumn{3}{|c|}{$>0.5$} & & \\
\hline
\end{tabular}

speciated $\mathrm{PM}_{2.5}$ and $\mathrm{PM}_{10}$ of anthropogenic origin. Based on two-letter abbreviations for each of the 12 modes, Fig. 1 and Table 1 summarize the chemical composition, modal standard deviations and initial radii.

Inter- and intra-modal coagulation is considered for anthropogenic Aitken and accumulation modes (modes labeled if, ic, so, jf and jc in Table 1) but omitted for the sea salt (sa, sb, sc) and dust modes (da, db, dc) and the $\mathrm{PM}_{10}$ mode (ca) as indicated by the dashed line in Fig. 1. Sources of MADE aerosols include primary emissions of SS, DU, POA, $\mathrm{BC}, \mathrm{PM}_{2.5}$ and $\mathrm{PM}_{10}$ and gas-to-particle conversion of $\mathrm{SO}_{4}$, $\mathrm{NO}_{3}, \mathrm{NH}_{4}$ and SOA. Emissions of SS (Lundgren, 2012) and DU (Vogel et al., 2006) are calculated online based on wind speed. Primary anthropogenic aerosols are based on emissions inventories. Emitted BC is assigned to the pure soot mode (so) and POA is distributed to the Aitken (if) and accumulation mode (jf) without soot core. The POA partitioning follows the emission preprocessor described in Knote (2012). Emissions are assumed to follow the initial modal size distributions summarized in Table $1 . \mathrm{SOA}, \mathrm{NO}_{3}$ and $\mathrm{NH}_{4}$ condense onto existing particles (Binkowski and Shankar, 1995). For sulfate, nucleation from the gas phase is additionally considered (Kerminen and Wexler, 1994) and particles are assigned to the soot-free Aitken mode (if). Hygroscopic growth of aerosols is based on ISORROPIA2 (Fountoukis and Nenes, 2007) for inorganic compounds and discussed in Athanasopoulou et al. (2013) for organic aerosol. As aerosol sinks, sedimentation and dry deposition (Riemer, 2002) and impaction scavenging (Rinke, 2008) by rain are considered. The description of impaction scavenging is based on an aerosol- and hydrometeor-size dependent collection efficiency. It considers inertial impaction and impaction from Brownian diffusion and interception but not phoretic effects. The parameterization is applied to the wet aerosol radius such that the hygroscopicity of an aerosol particle may affect its scavenging efficiency by impaction. Nucleation scavenging is not considered.

The M7 aerosol scheme considers four lognormal modes with soluble coating and three insoluble lognormal modes, including a nucleation mode but excluding giant modes. Table 1 compares the physical characteristics of these modes to the modes of MADE. M7 features a mode reorganization routine that transfers the largest particles within a mode to the next larger mode if the modal radius exceeds the boundaries indicated in the table. M7 includes fewer chemical species than MADE. It transports DU, SS, BC, POA and $\mathrm{SO}_{4}$. To be consistent with its simplified chemistry scheme, M7 sulfate is interpreted as sulfuric acid. M7 does not account for nitrogen species and secondary organic aerosols. The chemical composition of M7 modes is illustrated and compared to MADE in Fig. 1. Inter-modal coagulation is considered for all modes; intra-modal coagulation is neglected for the coarse modes (cs, ci) and accumulation mode dust (ai). Primary emissions are identical to MADE and follow MADE size distributions. They are assigned to M7 modes based on the mode correspondence shown in Table 1: BC is emitted into the insoluble carbon mode (ki), POA is partitioned to the soluble Aitken (ks) and accumulation mode (as) in the same way as for MADE. Giant dust and sea salt emission is ignored and accumulation and coarse-mode dust emissions are assigned to the pure dust modes (ai, ci) in M7. Sulfate can nucleate into the nucleation mode (ns) (default scheme used in this study: Kazil and Lovejoy, 2007; optional: Vehkamäki et al., 2002) or condense onto the larger soluble modes (ks, as, cs). Hygroscopic growth of the soluble modes (nc, ks, as, cs) is based on $\kappa$-Köhler theory (Petters and Kreidenweis, 2007). Aerosol removal by dry deposition and impaction scavenging follows the same parameterizations as for MADE. Table 2 summarizes the process differences of the $\mathrm{M} 7$ as compared to the MADE aerosol dynamics.

\subsection{Sulfur chemistry}

As part of the full gas-phase chemistry, COSMO-ART considers the following sulfur oxidation reactions:

$\mathrm{DMS}+\mathrm{NO}_{3} \rightarrow \mathrm{SO}_{2}$,
$\mathrm{DMS}+\mathrm{HO} \rightarrow \mathrm{SO}_{2}$,
$\mathrm{DMS}+\mathrm{HO} \rightarrow 0.4 \mathrm{DMSO}+0.6 \mathrm{SO}_{2}$, 
Table 2. Comparison of aerosol dynamical processes for MADE and M7.

\begin{tabular}{|c|c|c|}
\hline & M7 & MADE \\
\hline Coagulation & $\begin{array}{l}\text { coagulation and condensation coefficients for the transi- } \\
\text { tion regime based on flux-matching (Seinfeld and Pan- } \\
\text { dis, 2006, Fuchs theory) }\end{array}$ & $\begin{array}{l}\text { coagulation coefficients due to Brownian diffusion as } \\
\text { harmonic mean of free molecular regime and contin- } \\
\text { uum regime (Pratsinis, 1987) }\end{array}$ \\
\hline Condensation & all in-cloud sulfate is assumed to be in the aerosol phase & \multirow{2}{*}{$\begin{array}{l}\text { explicit treatment of condensation of sulfuric acid } \\
\text { (Binkowski and Shankar, 1995); thermodynamic bulk } \\
\text { equilibrium of inorganic and organic compounds and } \\
\text { water (Fountoukis and Nenes, 2007) }\end{array}$} \\
\hline Water uptake & $\kappa$-Köhler theory (Petters and Kreidenweis, 2007) & \\
\hline Nucleation & $\begin{array}{l}\text { explicit cluster-based parameterization } \\
\text { (Kazil and Lovejoy, 2007) }\end{array}$ & $\begin{array}{l}\text { binary nulceation of sulfuric acid and water with em- } \\
\text { pirical formulation for critical concentration of } \mathrm{H}_{2} \mathrm{SO}_{4} \\
\text { (Kerminen and Wexler, 1994) based on measurements } \\
\text { of Jaecker-Voirol and Mirabel (1989) }\end{array}$ \\
\hline
\end{tabular}

$\mathrm{DMSO}+\mathrm{HO} \rightarrow 0.6 \mathrm{SO}_{2}$,

$\mathrm{SO}_{2}+\mathrm{HO} \rightarrow \mathrm{SO}_{4}+\mathrm{HO}_{2}$,

where the reaction equations are restricted to prognostic species such that non-prognostic species have been omitted. Aqueous-phase chemistry, namely in-droplet oxidation of $\mathrm{SO}_{2}(\mathrm{aq})$, is not included in the standard setup. DMS emissions are calculated online based on wind speed (Nightingale et al., 2000). Anthropogenic gaseous emissions are based on inventory data. Dry deposition according to Baer and Nester (1992) and gas-to-particle conversion are considered as sinks of gas-phase species.

The efficient M7 chemistry consists of DMS, $\mathrm{SO}_{2}(\mathrm{~g})$, $\mathrm{SO}_{4}(\mathrm{~g})$ and $\mathrm{SO}_{4}(\mathrm{aq})$ as interactive variables and requires external input for the reactive oxidants $\mathrm{HO}, \mathrm{O}_{3}, \mathrm{NO}_{2}$ and $\mathrm{H}_{2} \mathrm{O}_{2}$. To prescribe theses species, spatially heterogeneous monthly mean values are typically used. A steady-state value for $\mathrm{NO}_{3}$ is additionally derived from the $\mathrm{NO}_{2}, \mathrm{O}_{3}$ and DMS input fields. The following sulfur oxidation reactions are considered.

- Aqueous-phase chemistry:

$$
\begin{aligned}
& \mathrm{SO}_{2}(\mathrm{aq})+\mathrm{H}_{2} \mathrm{O}_{2}(\mathrm{aq}) \rightarrow \mathrm{SO}_{4}(\mathrm{aq}) \\
& \mathrm{SO}_{2}(\mathrm{aq})+\mathrm{O}_{3}(\mathrm{aq}) \rightarrow \mathrm{SO}_{4}(\mathrm{aq})
\end{aligned}
$$

- Daytime gas-phase chemistry:

$$
\begin{aligned}
& \mathrm{DMS}(\mathrm{g})+\mathrm{HO}(\mathrm{g}) \rightarrow \mathrm{SO}_{2}(\mathrm{~g}) \\
& \mathrm{DMS}(\mathrm{g})+\mathrm{HO}(\mathrm{g}) \rightarrow \mathrm{SO}_{4}(\mathrm{~g}) \\
& \mathrm{SO}_{2}(\mathrm{~g})+\mathrm{HO}(\mathrm{g}) \rightarrow \mathrm{SO}_{4}(\mathrm{~g})
\end{aligned}
$$

- Nighttime gas-phase chemistry:

$$
\operatorname{DMS}(\mathrm{g})+\mathrm{NO}_{3}(\mathrm{~g}) \rightarrow \mathrm{SO}_{2}(\mathrm{~g})
$$

Non-prognostic products have been omitted. Day- and nighttime reactions are exclusive and the seasonal variability of day length is taken into account. Aqueous-phase chemistry requires the presence of cloud water but is independent of solar insolation. The dissolution of the gaseous species for the aqueous-phase reactions is based on the effective Henry constants determined by the cloud droplets $\mathrm{pH}$ value. Assuming that most cloud droplets have emerged from the activation of accumulation mode aerosol, $\mathrm{SO}_{4}(\mathrm{aq})$ resulting from the aqueous-phase reaction is in most cases assigned to the mixed accumulation mode (mode as in Fig. 1 and Table 1) and in fewer cases to the mixed coarse mode (mode cs). This is implemented by a number-based partitioning that favors the more numerous accumulation mode.

\subsection{Aerosol-radiation interactions}

The optical properties of MADE and M7 aerosol particles, i.e., extinction coefficient, single-scattering albedo and asymmetry factor are parameterized based on Mie calculations. Optical properties of MADE aerosols are distinguished on a modal basis such that for each mode a representative refractive index is assumed and calculations are performed for modal diameters of emitted particles (Table 1). The parameterization for mixed and anthropogenic modes is discussed by Vogel et al. (2009), for sea salt by Lundgren (2012) and for dust by Stanelle et al. (2010). In contrast to MADE, optical properties of M7 aerosol are species-based: the modal refractive index is the mass-weighted average of the refractive indices of the different species (Zubler et al., 2011). This method requires a look-up table of Mie properties, which also allows us to consider the simulated modal diameters instead of the values at emission applied in MADE.

\subsection{Aerosol-cloud interactions}

The activation of aerosol particles to cloud droplets is described in Bangert et al. (2011, 2012). The CCN spectrum is based on classical Köhler theory (Köhler, 1936) for hygroscopic aerosol (MADE modes if, ic, so, jf, jc, sa, sb, 
sc; M7 modes ns, ks, as, cs) and on adsorption theory (Kumar et al., 2011) for non-hygroscopic particles (MADE modes da, db, dc; M7 modes ki, ai, ci). Supersaturation follows the parameterization of Nenes and Seinfeld (2003) and Fountoukis and Nenes (2005), which is based on adiabatic parcel ascent. To take into account the sub-grid-scale updraft variability, the number concentration of activated aerosol particles is determined by numerically averaging over a Gaussian probability density function (PDF) of updraft velocities about the grid mean value rather than using the number concentration of particles that are activated for the grid mean updraft. The standard deviation of the PDF depends on the turbulent kinetic energy (TKE). The activation parameterization takes into account the competition of different particles and solves the supersaturation balance equation based on population splitting into kinetically limited and equilibrating activated aerosol particles. For cloud-base activation, entrainment of below-cloud aerosol is considered (Ghan et al., 1997). For in-cloud activation, the depletion of supersaturation by existing droplets is accounted for by treating these droplets as giant $\mathrm{CCN}$ following Barahona et al. (2010).

Ice nucleation is based on the empirical, aerosol-surfacebased INP spectrum of Phillips et al. (2008), which does not distinguish between different freezing modes. As an alternative, Ullrich et al. (2017) have recently derived and implemented nucleation spectra for immersion freezing of dust and deposition nucleation on dust and soot based on the icenucleation-active site approach and measurements from the AIDA cloud chamber. Table 3 summarizes how INP spectra are applied to MADE aerosols in the standard setup of COSMO-ART and to MADE and M7 aerosol for this study. The implementation of ice nucleation (Bangert et al., 2012) is based on Barahona and Nenes (2009a, b). For temperatures higher than the onset temperature of homogeneous freezing, i.e., $T>235 \mathrm{~K}$, grid-scale supersaturation with respect to ice is applied to determine the ice-nucleation rate from the INP spectrum. At lower temperatures, the competition of heterogeneous ice nucleation and homogeneous freezing of solution droplets is taken into account via the ice-supersaturation equation for an ascending parcel. For its updraft, a PDF about the grid mean value is applied.

The activation and ice-nucleation parameterizations are coupled to a two-moment microphysics scheme with five hydrometeor classes (cloud droplets, rain drops, ice crystals, snow flakes and graupel) (Seifert and Beheng, 2006; Noppel et al., 2010). This scheme does not distinguish between warm, mixed-phase and cirrus clouds, but its processes are based on temperature, saturation, and liquid and ice water content in the respective grid box. We will therefore use the term liquid cloud or warm cloud to denote cloudy regions without cloud ice, mixed-phase cloud to denote cloudy regions in which both cloud liquid and cloud ice are present, and ice cloud for regions which contain cloud water in the form of ice but no liquid. The latter may correspond to glaciated clouds or to cirrus clouds. We reserve the expression cirrus for ice clouds at temperatures lower than $235 \mathrm{~K}$, in which homogeneous freezing of solution droplets occurs.

The coupling of the activation and ice-nucleation routines to the cloud microphysics scheme is adapted from the standard setup of COSMO-ART and is identical for both aerosol schemes in this study. As for the standard version of COSMO-ART, neither liquid nor ice-phase nucleation scavenging is considered. The coupling of the parameterized number of activated aerosol particles to microphysics in the standard setup of COSMO-ART is based on the assumption that in-cloud activation is largely inhibited by the depletion of supersaturation on preexisting cloud droplets. CCN depletion is only accounted for by limiting the number of cloud droplets to the total number of soluble Aitken and accumulation mode particles. In this study, $\mathrm{CCN}$ depletion is taken into account by subtracting the number of existing cloud droplets from the number of newly activated droplets predicted by the activation parameterization.

In the standard setup, ice nucleation in mixed-phase as well as ice clouds is coupled to the cloud microphysics scheme based on the assumption that ice nucleation converts water vapor into ice. Ice nucleation in mixed-phase clouds is thus assumed to proceed purely by condensation nucleation (Table 3). For mixed-phase clouds in this study, we assume that immersion and contact freezing convert cloud droplets into ice crystals such that cloud droplet number concentration and mixing ratio are reduced by mixed-phase ice nucleation. Ice nucleation in ice clouds follows the previous approach of MADE and converts water vapor into ice. Unmodified from the standard setup, INP depletion is accounted for by a number adjustment that subtracts the existing number of ice crystals and snow flakes from the crystal number predicted by the parameterization.

\section{Setup}

Simulations for this study are performed for a Saharan dust outbreak reaching Europe in May 2008. Following Bangert et al. (2012), we choose a dust event to ensure sufficiently high INP concentrations inside our simulation domain in order to compare the implications of aerosol schemes not only on liquid-phase processes but also on ice-nucleation rates in mixed-phase and ice clouds. The domain covers the dust sources in northern Africa and extends to western and central Europe (Fig. 2). The model setup has a horizontal resolution of $25 \mathrm{~km}$ at a time step of $30 \mathrm{~s}$. The vertical resolution decreases with height, starting with $20 \mathrm{~m}$ in the surface layer and reaching $1000 \mathrm{~m}$ at the model top, corresponding to a height of $22 \mathrm{~km}$. We simulate a $90 \mathrm{~h}$ period, starting on 22 May, 00:00. To allow for spin-up of aerosol concentrations, we analyze the time average of the hourly output from the last $24 \mathrm{~h}$ of the simulation. 
Table 3. Coupling of aerosol modes to ice-nucleation parameterizations. The table summarizes which ice-nucleation modes are considered for the pure dust and soot modes and modes with dust and/or soot core, depending on the aerosol scheme and ice-nucleation parameterization. In the standard setup of COSMO-ART, the condensation freezing parameterization, which takes into account MADE aerosol, is combined with a droplet freezing routine from the cloud microphysics scheme, which is not coupled to MADE. Homogeneous freezing of solution droplets follows Barahona and Nenes (2009b).

\begin{tabular}{|c|c|c|c|c|c|c|}
\hline \multirow{3}{*}{ MADE modes } & \multirow[t]{2}{*}{ Pure DU } & \multirow[t]{2}{*}{ Coated DU } & \multirow[t]{2}{*}{ Pure BC } & \multirow[t]{2}{*}{ Coated BC } & \multicolumn{2}{|c|}{ Dissolved aerosol } \\
\hline & & & & & without core & with core \\
\hline & \multicolumn{2}{|c|}{$\mathrm{da}, \mathrm{db}, \mathrm{dc}^{1}$} & so & $\mathrm{ic}, \mathrm{jc}$ & if, jf, sa, sb, sc & $\mathrm{ic}, \mathrm{jc}$ \\
\hline M7 modes & ai, ci & as, cs & $\mathrm{ki}$ & $\mathrm{ks}$, as, cs & $(\mathrm{ns})^{2}$ & $\mathrm{ks}$, as, cs \\
\hline \multicolumn{7}{|c|}{ COSMO-ART with Phillips et al. (2008) (standard) } \\
\hline Ice phase/cirrus & \multicolumn{4}{|c|}{ deposition } & homogeneous & - \\
\hline Mixed phase & \multicolumn{4}{|c|}{$\begin{array}{c}\text { immersion (Bigg (1953), not coupled to MADE) } \\
\text { condensation }\end{array}$} & \multicolumn{2}{|l|}{-} \\
\hline \multicolumn{7}{|c|}{ MADE and M7 with Phillips et al. (2008) (this study) } \\
\hline Ice phase/cirrus & \multicolumn{4}{|c|}{ deposition } & \multicolumn{2}{|c|}{ homogeneous } \\
\hline Mixed phase & \multicolumn{4}{|c|}{ immersion + contact } & \multicolumn{2}{|l|}{-} \\
\hline \multicolumn{7}{|c|}{ MADE with Ullrich et al. (2017) (this study) } \\
\hline Ice phase/cirrus & \multicolumn{3}{|c|}{ deposition } & - & \multicolumn{2}{|c|}{ homogeneous } \\
\hline Mixed phase & \multicolumn{2}{|c|}{ immersion } & \multicolumn{2}{|c|}{-} & \multicolumn{2}{|l|}{-} \\
\hline \multicolumn{7}{|c|}{ M7 with Ullrich et al. (2017) (this study) } \\
\hline Ice phase/cirrus & deposition & - & deposition & - & \multicolumn{2}{|c|}{ homogeneous } \\
\hline Mixed phase & - & immersion & \multicolumn{2}{|c|}{-} & \multicolumn{2}{|l|}{-} \\
\hline
\end{tabular}

Meteorological initial and boundary conditions are provided by the global model GME (Majewski et al., 2002). For the full ART chemistry, initial and boundary conditions of gases with the exception of $\mathrm{DMS}, \mathrm{SO}_{2}$ and $\mathrm{SO}_{4}$ are based on the global chemistry model MOZART (Emmons et al., 2010). For DMS, $\mathrm{SO}_{2}, \mathrm{SO}_{4}$ and aerosols, no initial and boundary conditions are provided. Anthropogenic emissions follow the TNO/MACC inventory (van der Gon et al., 2010; Kuenen et al., 2011). The inventory does not provide emissions for Africa, so no anthropogenic but only natural emissions are considered in this region. Surface properties for parameterized emissions rely on the GLC2000 dataset (Bartholomé and Belward, 2005) and on Marticorena et al. (1997) for dust.

Table 4 summarizes the six different model settings used for this study. "Sim", "simSIG", "Passive" and "Coupled" simulations are performed with both MADE and M7. "SimAQ" and "simCL" simulations are specific to and only performed with M7 such that overall 10 simulations have been performed.

Aerosol-radiation interactions are disabled for all simulations; aerosol-cloud interactions are restricted to Cou- pled simulations. All other simulations thus feature passive aerosols such that the simulated meteorology is identical for simulations with MADE and M7. Without aerosol-cloud interactions, the two-moment cloud microphysics is not required. We therefore employ the operational one-moment scheme (Reinhardt and Seifert, 2006) in simulations with passive aerosol.

Sim simulations aim to make the model setup of M7 and MADE as similar as possible: the M7-only aqueous-phase chemistry, the MADE-only giant modes, and $\mathrm{SOA}, \mathrm{NO}_{3}$, $\mathrm{NH}_{4}$ and unspeciated $\mathrm{PM}_{2.5}$ as MADE-only species are disabled; a universal standard deviation of $\sigma_{\text {universal }}=1.7$ is used for all MADE and M7 modes instead of the default standard deviations indicated in Table 1; for the oxidant fields required by the $\mathrm{M} 7$ chemistry hourly outputs of the respective fields from MADE simulations are used instead of climatological values. Sim simulations aim to investigate the sensitivities of aerosol burden, aerosol size distribution and gas-phase chemistry without taking into account the disabled structural differences.

Passive simulations correspond to default setups of MADE and M7 and allow us to explore additional sensitivities aris- 
ing from aqueous-phase chemistry, climatological oxidant fields, different modal standard deviations and additional aerosol species. For these simulations, we additionally investigate the optical and cloud- and ice-forming properties of the aerosol distributions by offline diagnostics: routines for optical properties, droplet activation and ice nucleation are called without passing the results on to the cloud microphysics and radiation scheme of the model. The ice-nucleation routine is called in mixed-phase setting when the one-moment cloud microphysics scheme predicts both cloud ice and cloud water and in ice-phase setting when cloud water is absent. The activation routine is applied in its setting for new cloud formation, i.e., without cloud-base entrainment of aerosol and without considering supersaturation depletion by existing droplets. It is called in all grid boxes where cloud water is predicted by the one-moment scheme. For computational reasons, the updraft PDF is replaced by applying an updraft $w^{*}=w+0.8 \sqrt{\mathrm{TKE}}$, where $w$ is the grid-scale updraft and TKE denotes the sub-grid-scale turbulent kinetic energy (Bangert, 2012).

SimSIG, simAQ and simCL simulations feature settings intermediate to sim and Passive and are intended to individually investigate the effects of modal standard deviation, aqueous-phase chemistry or climatological oxidant fields, respectively. Coupled simulations with two-moment microphysics and aerosol-cloud coupling are conducted to investigate the relationship between CCN, INPs, cloud droplet and ice crystal numbers. In Coupled simulations, the same updraft parameterization as in Passive simulations (i.e., no PDF) is applied for the online as well as offline calculation of $\mathrm{CCN}$.

\section{Results from the sensitivity experiments}

Figure 2 illustrates the dominant transport patterns for aerosols on the analysis day: following the transport from Africa over the Mediterranean to central Europe, the flow turns to a low-pressure system off the Bay of Biscay. The corresponding $\mathrm{M} 7$ aerosol burdens of sea salt, dust, $\mathrm{BC}$ and POA are illustrated in Fig. 3 (left column): dust is transported from the Saharan source regions over the Mediterranean Sea to the southern parts of Germany and France. Sea-salt-containing maritime air is advected over most of the domain, with the exception of eastern Africa. Strong winds south of Britain explain the strongest sea salt emissions and burdens in this region. For the African part of the domain, no anthropogenic emissions are available. Accordingly, BC and POA are largely restricted to continental Europe, the Mediterranean Sea and the Atlantic part of the domain. The corresponding $\mathrm{SO}_{4}$ burden is depicted in Fig. 4 (middle row). It is restricted to the northern and western half of the domain because continental Africa neither provides anthropogenic emissions of $\mathrm{SO}_{2}$ nor natural DMS-derived sulfate. In some parts of the following analysis we distin-

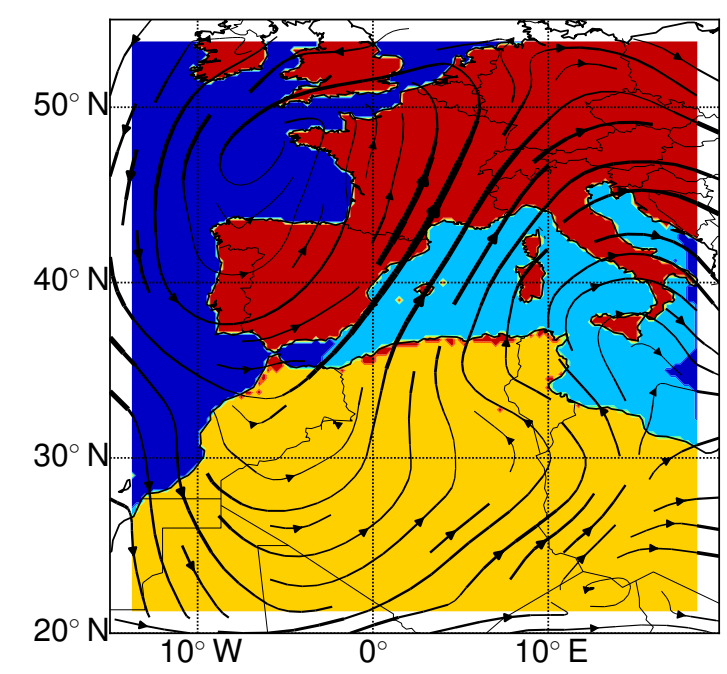

Figure 2. Aerosol mass transport as represented by the weighted vertical average $\langle x\rangle=\sum_{i} w_{i} x_{i} / \sum_{i} w_{i}$ of the horizontal wind field $x$ where weights $w$ are given by the total dry aerosol mass concentration. Wind direction is indicated by arrow heads and its strength encoded in line thickness where the thickest lines correspond to $40 \mathrm{~m} \mathrm{~s}^{-1}$. The background colors illustrate the geographic regions Africa (yellow), Mediterranean Sea (light blue), Europe (red) and Atlantic (dark blue). See main text for details of region definitions.

guish between different regions based on aerosol composition (Fig. 2): the region denoted as "Atlantic" comprises maritime regions in which surface dust is absent; the expression "Mediterranean", in contrast, characterizes dusty maritime regions. "Europe" stands for continental areas with anthropogenic emissions and "Africa" for continental sites without anthropogenic emission.

Aerosol burdens for MADE and M7 agree within $20 \%$ (Fig. 3, Table 5), which confirms our strategy for sim simulations in choosing the setup such that MADE and M7 are very similar. Dust burdens are identical for M7 and MADE: the transfer of dust into the soluble M7 modes via condensation is ineffective (coagulation is neglected due to large particle sizes; Sect. 2) such that MADE and M7 both describe dust by two identical pure modes. The low coating in sim simulation is a result of a general underestimation of sulfate in this setup (cf. Table 7). The M7 sea salt burden is increased by $\sim 20 \%$ as compared to MADE, while the $\mathrm{SO}_{4}$ burden is decreased by $\sim 20 \%$. BC and POA burden are decreased by less than $10 \%$. The following discussion of sim, simSIG, simAQ and simCL simulations is greatly facilitated by this similarity.

\subsection{Sensitivities of aerosol size distributions and removal}

Primary emissions are identical for simulations with MADE and M7 (Sect. 2) such that differences in primary aerosol burdens are attributable to the aerosol sinks, i.e., dry deposition and impaction scavenging. Differences in sulfate burden be- 

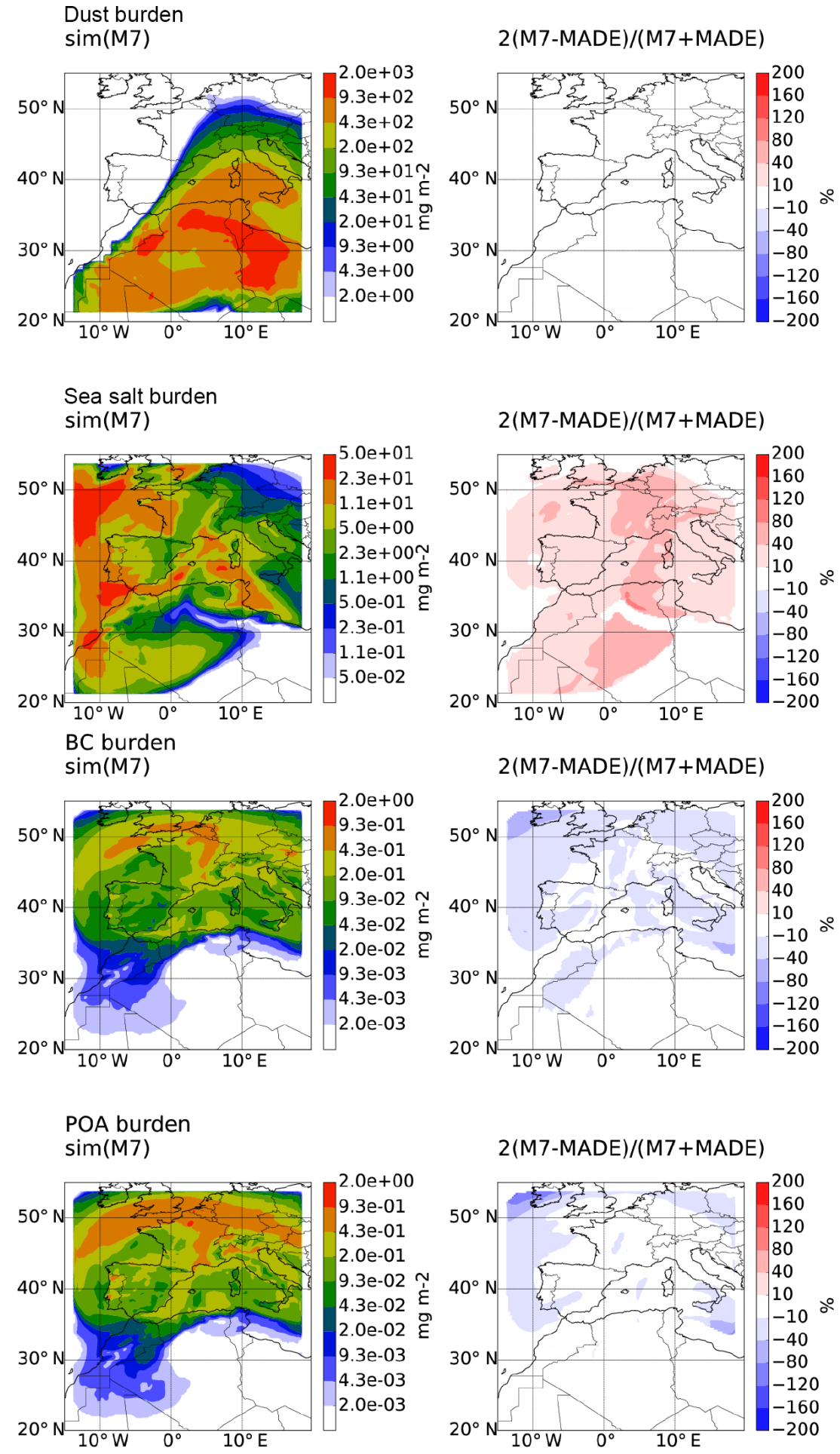

Figure 3. Aerosol burdens of dust (first row), sea salt (second row), BC (third row) and POA (last row) for M7 (left column; data points exceeding the scale have been clipped to the maximum value) and differences to MADE (right column; to prevent diverging values, percentage differences $\left(f_{1}-f_{2}\right) /\left[0.5\left(f_{1}+f_{2}\right)\right], f_{1}: \mathrm{M} 7, f_{2}$ : MADE, are only determined for data points with $f_{1 / 2}($ lat, long $)>0.01 \cdot P_{95}\left(f_{1}\right)$, where lat and long denote latitude and longitude of the horizontal position and $P_{95}$ the 95th percentile of all data points in the domain) for sim simulations. Unless explicitly mentioned otherwise, aerosol burdens refer to dry aerosol mass. 
Table 4. List of simulations. A "y" shows that a model feature is active if applicable (aqueous-phase chemistry and climatological oxidant fields are only active for M7 simulations and giant modes only apply to MADE simulations). An " $n$ " indicates it is not active. See main text for details.

\begin{tabular}{|c|c|c|c|c|c|c|c|c|}
\hline 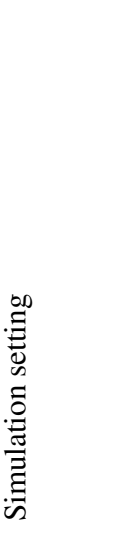 & 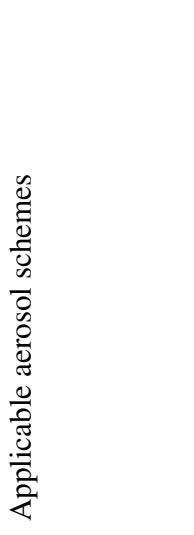 & 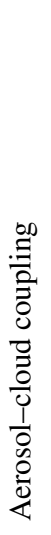 & 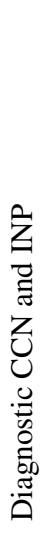 & 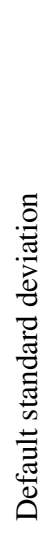 & 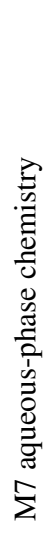 & 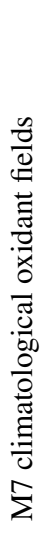 & 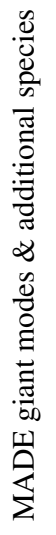 & Subject of investigation \\
\hline $\operatorname{sim}$ & M7 \& MADE & $\mathrm{n}$ & $\mathrm{n}$ & $\mathrm{n}$ & $\mathrm{n}$ & $\mathrm{n}$ & $\mathrm{n}$ & gas-phase chemistry, aerosol burden, size distributions \\
\hline simSIG & M7 \& MADE & $\mathrm{n}$ & $\mathrm{n}$ & y & $\mathrm{n}$ & $\mathrm{n}$ & $\mathrm{n}$ & modal standard deviation \\
\hline $\operatorname{sim} A Q$ & M7 & $\mathrm{n}$ & $\mathrm{n}$ & $\mathrm{n}$ & $\mathrm{y}$ & $\mathrm{n}$ & $\mathrm{n}$ & aqueous-phase chemistry \\
\hline $\operatorname{simCL}$ & M7 & $\mathrm{n}$ & $\mathrm{n}$ & $\mathrm{n}$ & $\mathrm{y}$ & $\mathrm{y}$ & $\mathrm{n}$ & oxidant fields \\
\hline Passive & M7 \& MADE & $\mathrm{n}$ & $\mathrm{y}$ & $\mathrm{y}$ & $\mathrm{y}$ & $\mathrm{y}$ & $\mathrm{y}$ & comparison of default setups, radiative and cloud-forming properties \\
\hline Coupled & M7 \& MADE & $\mathrm{y}$ & $\mathrm{y}$ & $\mathrm{y}$ & $\mathrm{y}$ & $\mathrm{y}$ & $\mathrm{y}$ & effect of CCN/INP differences on cloud droplet and ice crystal number \\
\hline
\end{tabular}

tween MADE and M7 are likewise dominated by differences in removal and not in the sulfate production rate (Fig. 4).

The efficiency of both removal processes depends on particle size and becomes inefficient if particle radii approach the Greenfield gap at $0.1 \mu \mathrm{m}$. Whether a shift in the size distribution results in increased or decreased removal depends on its relative position to the Greenfield gap: a shift in an Aitken mode to smaller sizes or of a coarse mode to larger sizes enhances removal. The effect of an accumulation mode shift depends on the details of the Greenfield gap and cannot easily be predicted. Removal is dominated by impaction scavenging in the cloudy northern half of the domain, where the abundance of sulfate, sea salt, BC and POA is largest. Only for dust is dry deposition important, especially in the African source regions (not shown).

\subsubsection{Sensitivity of size distribution to modal composition}

Figure 5 depicts domain-averaged volume size distributions of different species for MADE and M7 obtained from sim simulations (red). The size distribution of M7 sea salt is shifted to smaller particle sizes as compared to MADE. This is a result of the internal mixture of sea salt in M7 as compared to the externally mixed sea salt modes of MADE (Table 1): sea salt emissions only contribute a fraction of the total number of particles in the M7 mixed modes such that the average sea salt mass per mixed aerosol particle is reduced as compared to the average mass of emitted particles and the corresponding size of MADE sea salt. For dust, not only the burdens but also the size distributions are effectively identical for MADE and M7.

While MADE-sulfate is found in a single broad peak of a large Aitken or small accumulation mode, M7 sulfate mass shows a distinct trimodal structure. The position of the pronounced M7 sulfate coarse mode corresponds to that of coarse-mode sea salt. As dust is hardly coated and BC and POA are not abundant in the coarse-mode size range, the mixed M7 coarse mode corresponds to sulfate-coated sea salt. In contrast, the MADE sea salt coarse mode is not significantly coated. The M7 coarse-mode coating could be more effective because sea salt is more abundant and particles are smaller such that a larger surface for condensation is available. In addition, while MADE sulfate is restricted to condensation as a process for transfer into the coarse mode, M7 sulfate can additionally be transferred from the accumulation to the coarse mode by mode reorganization once the median radius exceeds the maximum value for its mode.

The separated Aitken and accumulation mode peaks in M7 sulfate as compared to the single peak for MADE correspond to the $\mathrm{BC}$ and POA size distributions: M7 BC is located at smaller size and M7 POA at larger ones than for MADE. The location of the M7 POA peak corresponds to the M7 accumulation mode sea salt peak and indicates that POAcontaining particles in M7 are enlarged by internal mixture with sea salt. The increase in MADE accumulation mode BC as compared to $\mathrm{M} 7$ likely results from different strategies to describe growth by condensation in MADE and M7: for both schemes, BC is emitted into a pure Aitken mode and rapidly coated. In M7, coated BC is assigned to the mixed Aitken 
Table 5. Horizontal averages of relative differences. $\Delta=2(\mathrm{M} 7-\mathrm{MADE}) /(\mathrm{M} 7+\mathrm{MADE})$ between MADE and M7 in percent for sim and Passive simulations. Values correspond to Figs. 3, 4, 8, 9 and 10, where production rates are vertically integrated and concentrations are vertically averaged. With the exception of secondary inorganic aerosol (SIA, see text) and accumulation and coarse-mode burden, aerosol burden and $\mathrm{SO}_{4}$ production and removal are not illustrated for the Passive simulation. AOD (aerosol optical depth) and CCN are not shown for sim simulation. If not explicitly stated otherwise, aerosol burdens correspond to dry aerosol mass. OA: organic aerosol.

\begin{tabular}{lrr}
\hline & sim & Passive \\
\hline $\mathrm{SO}_{4}$ production rate (domain average) & 8 & 196 \\
$\mathrm{SO}_{4}$ aerosol burden (domain average) & -8 & 134 \\
$\mathrm{SO}_{4}$ aerosol burden (average over upper-left quadrant of domain) & 138 \\
$\mathrm{SO}_{4}$ dry and wet removal rate (domain average) & 22 & 152 \\
\hline SIA burden (average over Atlantic) & 122 & -40 \\
SIA burden (average over Mediterranean Sea) & -22 & 30 \\
Dust burden (domain average) & -88 \\
Sea salt burden (domain average) & 0 & 54 \\
OA burden (domain average) & -36 \\
BC burden (domain average) & -6 & -8 \\
\hline AOD (average over upper-left quadrant of domain) & -12 \\
AOD (average over lower-right quadrant of domain) & 18 & -20 \\
Wet accumulation and coarse-mode burden (average over upper-left quadrant of domain) & -56 \\
Wet accumulation and coarse-mode burden (average over lower-right quadrant of domain) & 0 & -22 \\
\hline CCN number concentration in liquid clouds (domain average) & -108 \\
CCN number concentration in mixed-phase clouds (domain average) & -114 \\
\hline
\end{tabular}

mode and can subsequently be transferred to the accumulation mode by mode reorganization (Vignati et al., 2004). The extent of the mode reorganization is not directly coupled to the size of the coated soot particles but to the characteristics of the mixed Aitken mode with sizes being influenced by, e.g., the transfer of small particles from the nucleation mode or the transfer of large particles to the accumulation mode. The MADE coating routine directly assigns a fraction of the newly coated BC to the accumulation mode (Riemer, 2002).

The differences in aerosol burdens between MADE and M7 can be traced back to the size distributions: the M7 sulfate burden is decreased in comparison to MADE in the northern part of the domain due to increased removal of M7 coarse-mode sulfate. The burden of M7 sea salt is increased due to the smaller size of the mixed coarse mode as compared to the MADE sea salt coarse mode, which results in less efficient impaction scavenging for M7. The BC burden of M7 is smaller than that of MADE because of increased removal due to the smaller sizes of BC-containing particles in M7. The decrease in M7 POA burden can be explained by the position of the M7 mixed accumulation mode being shifted away from the Greenfield gap as compared to the MADE accumulation modes.

\subsubsection{Sensitivity of size distribution to modal standard deviation}

The effect of the modal standard deviation $\sigma$ on the size distribution is illustrated in Fig. 5. Plotting the data of sim sim- ulations with the default standard deviations of the aerosol schemes (green; see Table 1 for values of $\sigma_{\text {default }}$ ) instead of the universal standard deviation $\sigma_{\text {universal }}=1.7$ used to generate the data illustrates the structural effect of the standard deviation as opposed to the effects arising from the influence of $\sigma$ on aerosol microphysical processes. The structural effect is most pronounced for dust: with $\sigma_{\mathrm{da}}=1.7=\sigma_{\text {universal }}$, the width of the MADE accumulation mode remains unchanged, while the MADE coarse mode becomes slightly narrower with $\sigma_{\mathrm{db}}=1.6$. For $\mathrm{M} 7$, the default accumulation mode is narrowed $\left(\sigma_{\mathrm{ai}}=1.59\right)$ and the default coarse mode broadened $\left(\sigma_{\mathrm{ci}}=2\right)$.

The effect of $\sigma$ on aerosol microphysics can be assessed by comparing the differences between the sim simulation plotted with default standard deviations (green) and simSIG simulations where the size distributions were generated using the default standard deviations (black). Effects are strongest for the coarse modes of dust and sea salt. Dust mass in the coarse mode is determined by the efficiency of dry deposition, which is the dominant removal process in the cloudfree African source regions. The sedimentation velocity of a lognormal mode is given by $v_{\text {sedi }} \propto r^{2} \exp \left(8 \ln ^{2} \sigma\right.$ ) (Slinn and Slinn, 1980) such that dry deposition is increased for larger $\sigma$, which corresponds to an increased number of very large particles. The dust burden of MADE accordingly increases by $4 \%$ when applying the smaller default standard deviation, while the M7 dust burden decreases by about $20 \%$ for the enlarged $\sigma_{\mathrm{ci}}$. A similar argument for the impaction scavenging of coarse-mode sea salt explains a $40 \%$ decrease in MADE 

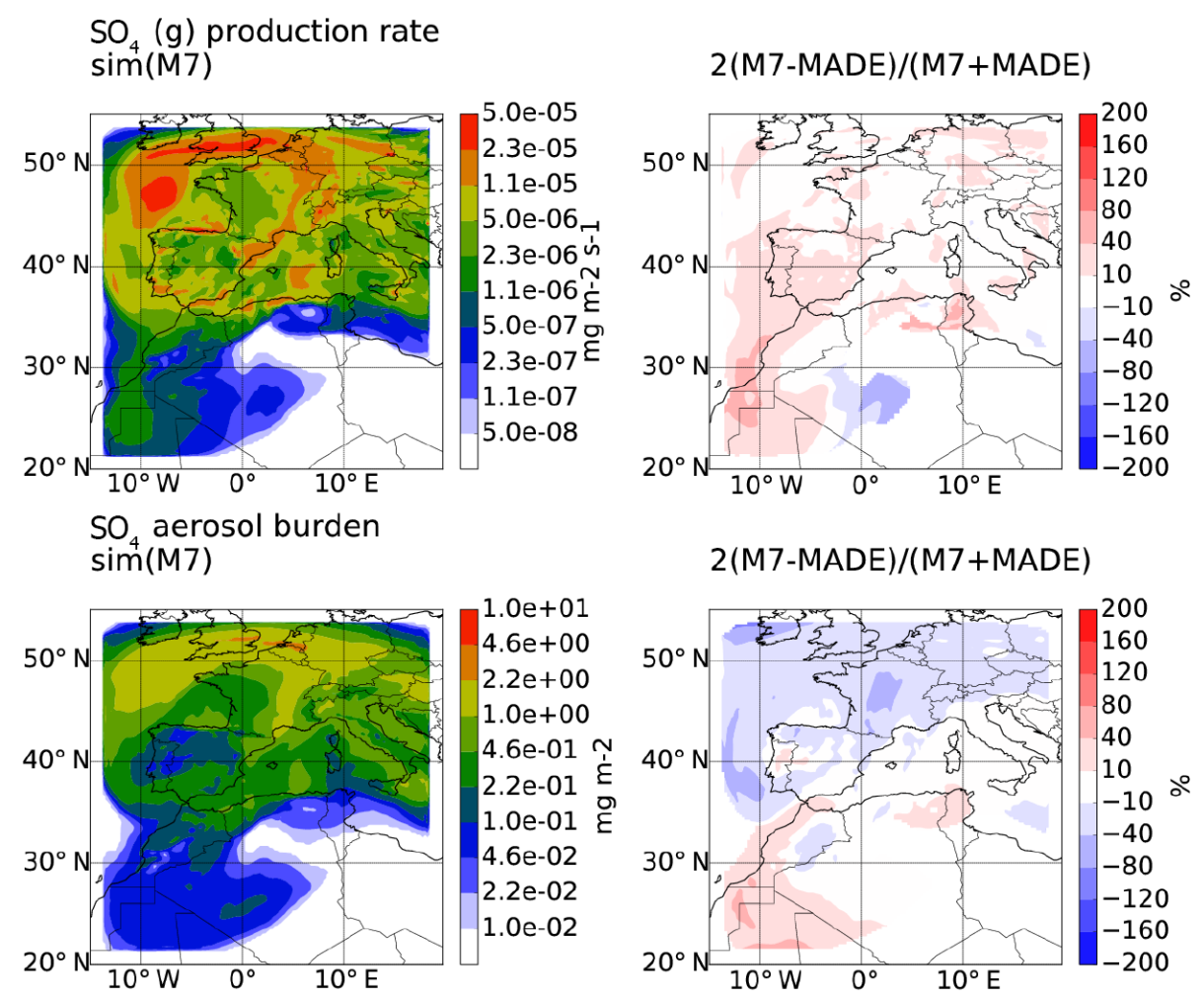

\section{$\mathrm{SO}_{4}$ dry \& wet removal rate $\operatorname{sim}(M 7)$}
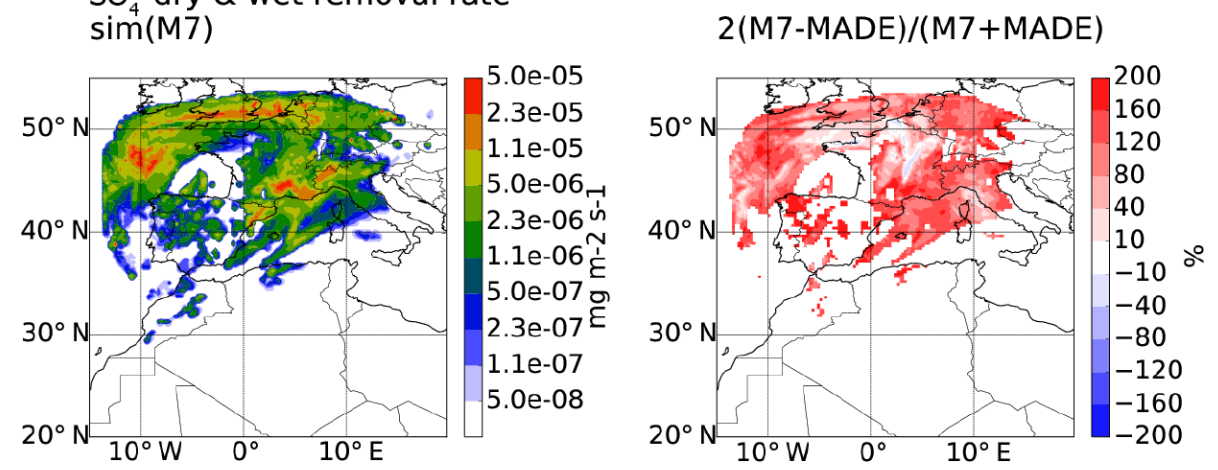

Figure 4. Sulfate budget for sim simulations. Comparison of M7 (left column) to MADE (percentage-difference plots in the right column) in terms of the vertical integral of the gas-phase production rate of $\mathrm{SO}_{4}$ (first row), sulfate burden (second row), and the sum of dry deposition and vertically integrated impaction scavenging rate of sulfate (last row). See Fig. 3 for plot details.

and M7 sea salt burden when using $\sigma_{\text {default }}=\sigma_{\mathrm{cs}}=\sigma_{\mathrm{sb}}=2$ instead of $\sigma_{\text {universal. }}$.

\subsection{Sensitivity of chemical sulfate production to aqueous-phase reactions and oxidant fields}

Figure 4 compares the chemical sulfate production as sources of atmospheric sulfate arising from MADE and M7 aerosol dynamics with full and efficient gas-phase sulfate chemistry for sim simulations (recall from Sects. 2.2 and 3 that nitrate chemistry is not considered). With domain-averaged differences below $10 \%$ (Table 5), the M7 gas-phase chemistry
(Eqs. R7-R11) and the ART chemistry (Eqs. R1-R5) are equally efficient in producing $\mathrm{SO}_{4}$.

The importance of aqueous-phase chemistry as a source of atmospheric sulfate aerosol is illustrated in Fig. 6. The aqueous-phase reaction rate in the simAQ simulation is about 2 times larger than the gas-phase reaction rate in the sim simulation without aqueous-phase chemistry (compare Figs. 4 and 6). As the occurrence of $\mathrm{SO}_{2}$ coincides with cloudy conditions in the northern and western part of the domain, the aqueous-phase reaction efficiently consumes $\mathrm{SO}_{2}$ and leads to an $80 \%$ reduction in its concentration as compared to the sim simulation (Table 6 ). The gas-phase reaction 
- M7 (sim) ---- MADE (sim) - M7 (sim + $\left.\sigma_{\text {default }}\right)$---- MADE $\left(\operatorname{sim}+\sigma_{\text {default }}\right)-$ M7 (simSIG) --- MADE $(\operatorname{simSIG})$
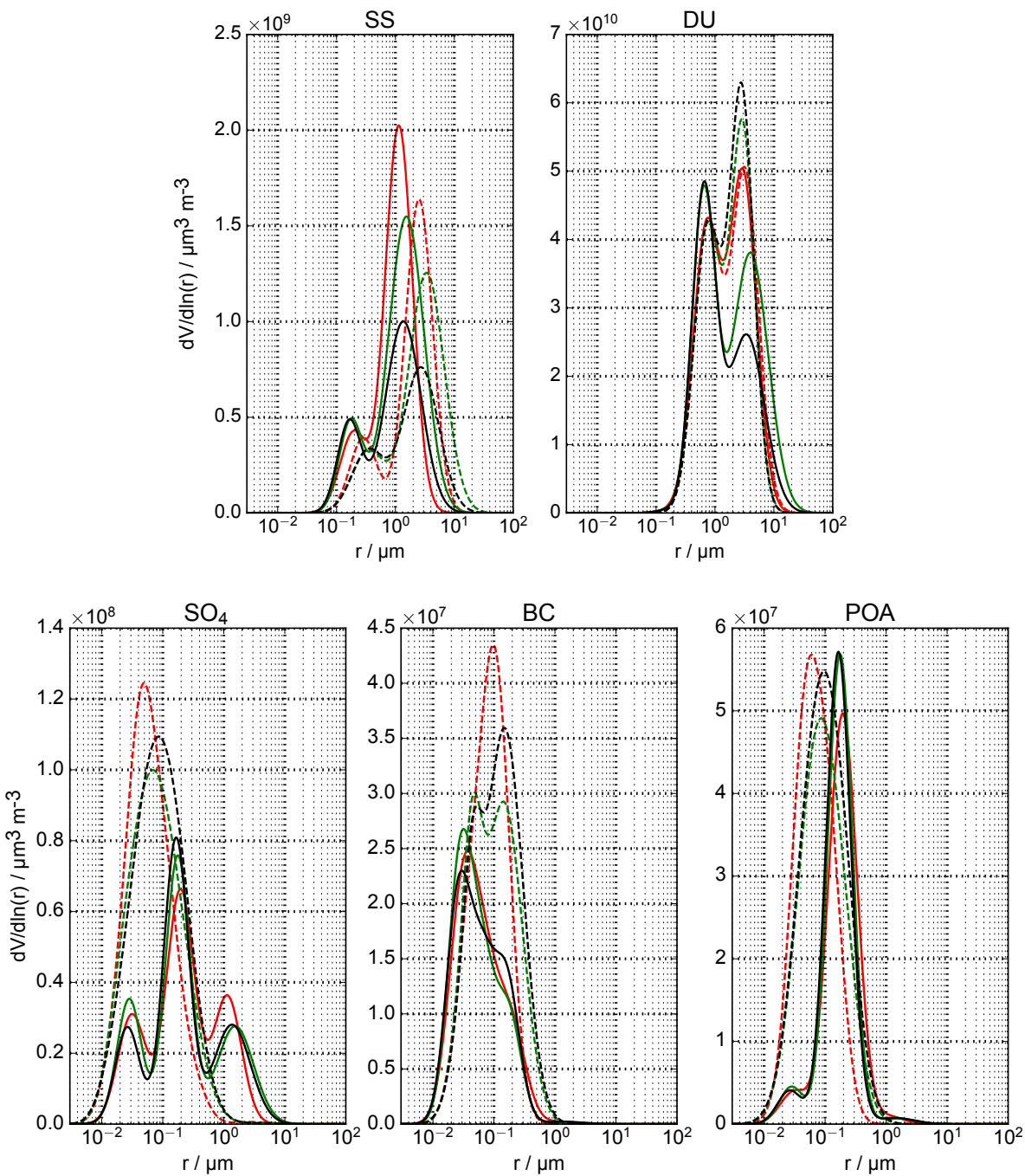

Figure 5. Domain-averaged volume distributions for different species and standard deviations. Species include $\mathrm{SS}, \mathrm{DU}$, sulfate $\left(\mathrm{SO}_{4}\right)$, $\mathrm{BC}$ and POA. Individual lognormal modes are determined from the vertical sum and horizontal average of the corresponding dry masses and numbers. The full, multimodal distribution emerges as the sum of individual lognormal modes. For mixed modes, lognormal modes of individual species are obtained by weighting the mixed-modal distribution by the fraction that the respective species contributes to the total mass in the mixed mode. The figure compares sim simulations, generated with the universal standard deviation $\sigma_{\text {universal }}=1.7$ for all modes (red), sim simulations but plotted using default standard deviations $\sigma_{\text {default }}$ as given in Table 1 (green), and simSIG simulations, generated with $\sigma_{\text {default }}$ (black).

rate in the simAQ simulation is reduced by $100 \%$ in comparison to sim due to the competition with the aqueous-phase reaction for $\mathrm{SO}_{2}$. The resulting sulfate burden of simAQ is increased by $140 \%$ as compared to sim.

The use of monthly-mean climatological oxidant fields instead of hourly values simulated by the full ART gas-phase chemistry influences the sulfate burden by less than $10 \%$ (Fig. 6, Table 6). The almost identical results in our case are the consequence of compensating effects on the aqueousphase reaction rates, which dominates total sulfate produc- tion: a $40 \%$ reduction in the $\mathrm{H}_{2} \mathrm{O}_{2}$ climatological oxidant field as compared to the detailed chemistry is largely compensated for by a $12 \%$ increase in $\mathrm{O}_{3}$ (Table 6) and thus only results in a $2 \%$ reduction in aqueous-phase production of sulfate (Fig. 6, Table 6). The gas-phase production rate of sulfate exhibits an inconsequential signal, which probably emerges from the interplay of enhancing effects of a locally dampened aqueous-phase reaction rate and dampening effects of decreases in the climatological concentrations of 

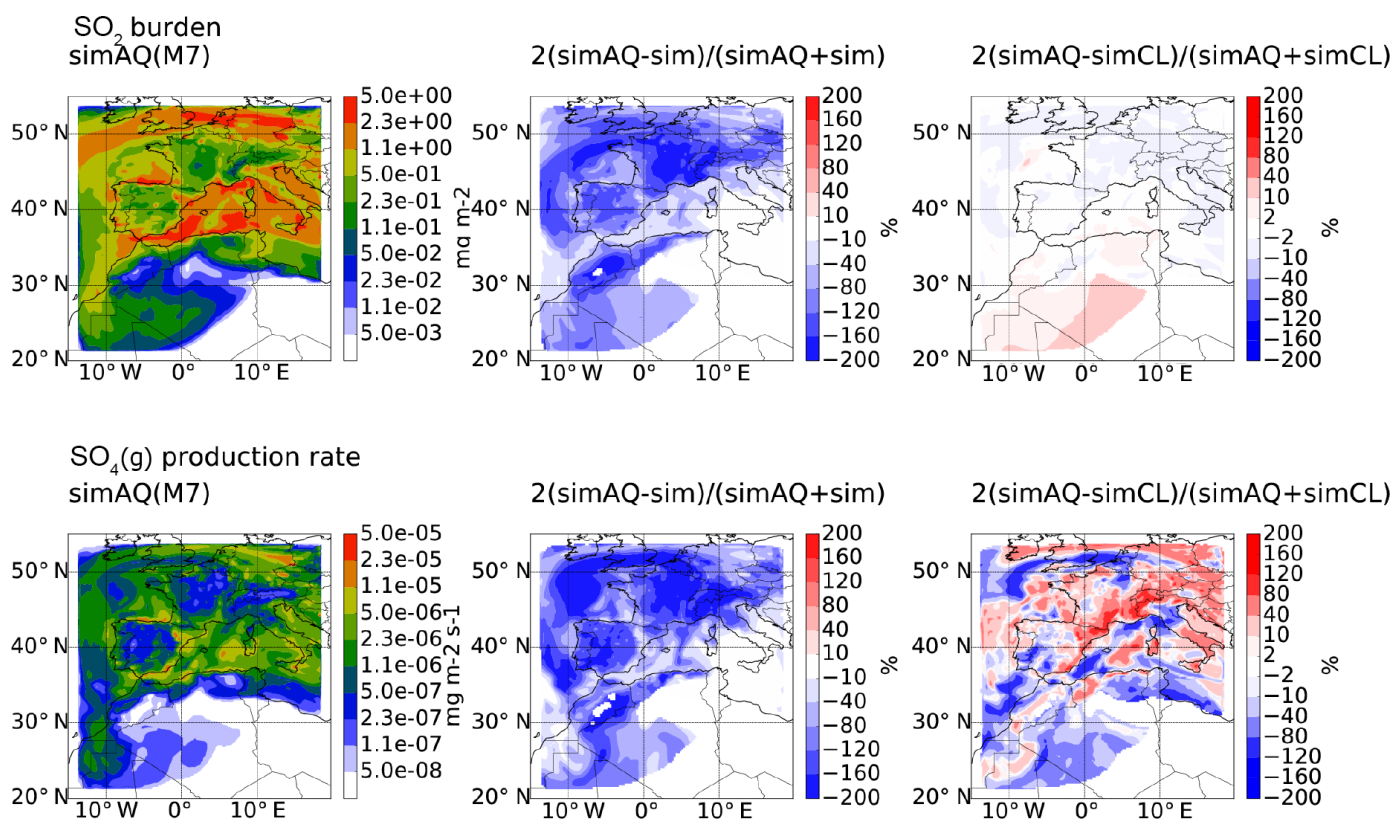

\section{$\mathrm{SO}_{4}(\mathrm{~g})$ production rate $\operatorname{sim} A Q(M 7)$}
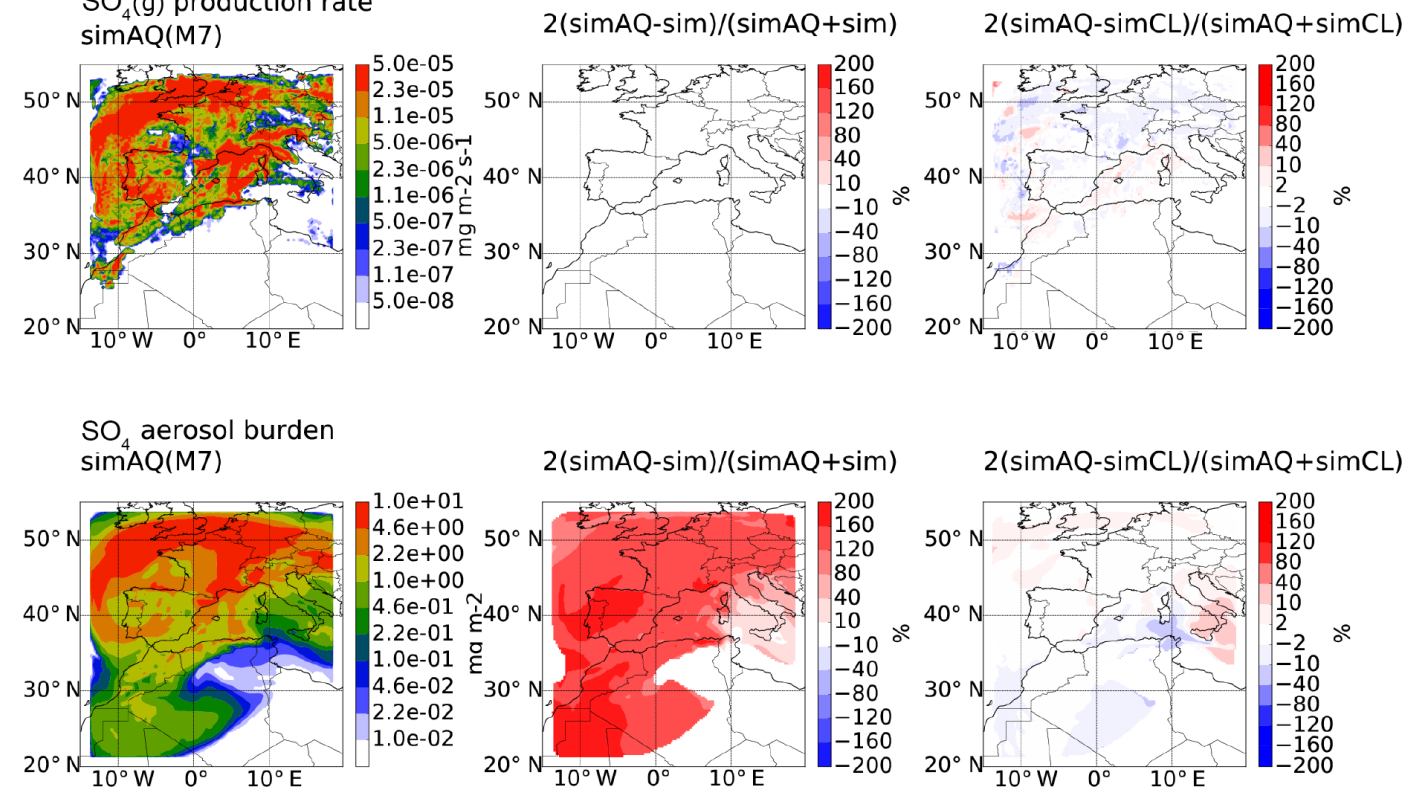

Figure 6. Sulfate production from aqueous-phase chemistry and using climatological oxidant fields. The figure compares the simAQ simulation (left columns) to sim (percentage-difference plots in the middle column) and simCL simulations (percentage-difference plots in the right column; note the different color scales). The first and fourth rows show the burden of $\mathrm{SO}_{2}$ and sulfate aerosol. The second and third rows depict vertical integrals of gas- and aqueous-phase production rates of $\mathrm{SO}_{4}$. See Fig. 3 for plot details.

$\mathrm{OH}$ and $\mathrm{NO}_{2}$ by 60 and $80 \%$, respectively, as compared to the hourly values (Fig. 6, Table 6).

The effect of the different chemistry setups on the sulfate level is summarized in Table 7, which compares the average surface concentrations of $\mathrm{SO}_{4}$ over continental Europe. According to, e.g., Fountoukis et al. (2011), concentrations of about $1-2 \mu \mathrm{gm}^{-3}$ are expected. These values are not reached with gas-phase sulfate chemistry alone but require the efficient aqueous-phase reaction, which is consistent with the findings of previous studies and especially by Knote et al. (2011).

\section{Results from comparison of default setups}

Differences in the sulfate budgets of MADE and M7 in their default configuration (Passive simulations according to Table 4) are dominated by the M7-only aqueous-phase chemistry (Table 5). As discussed in the previous section, 
Table 6. Horizontal averages of relative differences. $\Delta=2(\operatorname{sim} A Q-x) /(\operatorname{sim} A Q+x)$ between different $\mathrm{M} 7$ chemistry setups in percent for the simAQ simulation in comparison to simulations $\mathrm{x}=\mathrm{sim}$, simCL. Values of $\mathrm{SO}_{2}$ and $\mathrm{SO}_{4}$ correspond to Fig. 6, where the productions rates are vertically integrated. Differences in oxidant fields are based on weighted vertical averages as in Fig. 2, with the gas-phase production rate of $\mathrm{SO}_{4}$ as weight for the gas-phase oxidant $\mathrm{OH}$ and gas-phase oxidant precursor $\mathrm{NO}_{2}$ and weighted with the aqueous-phase reaction rate for the aqueous-phase oxidants $\mathrm{H}_{2} \mathrm{O}_{2}$ and $\mathrm{O}_{3}$. Where the sign of a difference signal is not uniform throughout the domain, representative quadrants have been chosen.

\begin{tabular}{lrr}
\hline & sim & simCL \\
\hline $\mathrm{SO}_{2}$ burden (domain average) & -78 & 0 \\
$\mathrm{SO}_{4}($ g) production rate (domain average) & -94 & -6 \\
$\mathrm{SO}_{4}($ aq) production rate (domain average) & 200 & -2 \\
$\mathrm{SO}_{4}$ aerosol burden (domain average) & 140 & 0 \\
\hline $\mathrm{OH}$ (average over upper-right quadrant of domain) & 0 & 62 \\
$\mathrm{OH}$ (average over lower-left quadrant of domain) & 0 & -20 \\
$\mathrm{NO}_{2}$ (domain average) & 0 & 84 \\
$\mathrm{O}_{3}$ (domain average) & 0 & -12 \\
$\mathrm{H}_{2} \mathrm{O}_{2}$ (average over upper-right quadrant of domain) & 0 & 40 \\
\hline
\end{tabular}

aqueous-phase chemistry is about twice as efficient in oxidizing $\mathrm{SO}_{2}$ as the gas-phase chemistry. The M7 sulfate burden is increased by about $140 \%$ for aqueous- and gasphase chemistry ( $\operatorname{sim} A Q)$ as compared to gas-phase chemistry alone ( $\mathrm{sim})$. In the sim simulation, the different gasphase chemistries for M7 and MADE result in almost identical sulfate burdens. Consequently, when comparing M7 with gas- and aqueous-phase chemistry to MADE in Passive simulations, a $140 \%$ increase for M7 is observed (Table 5). Comparing the size distribution of M7 sulfate mainly produced by aqueous-phase chemistry (Fig. 7) to that produced by the gas-phase reaction (Fig. 5) illustrates that the aqueous-phase chemistry deposits sulfate mainly into the accumulation and to a lesser extent into the coarse mode (the partitioning between these two modes is based on number and thus favors the more numerous accumulation mode), while gas-phase chemistry additionally transfers sulfate to Aitken modes particles via condensation or coagulation with nucleation-mode particles.

As discussed, M7 aqueous chemistry produces much higher sulfate concentrations, while MADE also contains nitrate and ammonium as additional inorganic soluble species. Similar to different secondary organic aerosol (SOA) species, which are often lumped together, we combine sulfate, nitrate and ammonium into a secondary inorganic aerosol (SIA) class, to obtain a quantity that can be compared between MADE and M7. Note that for M7, SIA is identical to sulfate aerosol. From this perspective, the higher contribution of M7 sulfate to the total aerosol burden is compensated for by MADE nitrate and ammonium (Fig. 8). In the Atlantic part of the domain, overcompensation occurs and the SIA burden is reduced by about $40 \%$ for M7 as compared to MADE (Table 5). The SIA burden in the central (Mediterranean) part of the domain is increased by about $30 \%$ for $\mathrm{M} 7$ in comparison to MADE.
The sea salt size distributions of MADE and M7 from Passive simulations (not shown) are qualitatively similar to the sim simulation (Fig. 5). The impaction scavenging efficiency of sea salt remains higher for MADE than for M7. This effect is not compensated for by additional sea salt mass in the MADE giant mode, keeping the sea salt burden of M7 enhanced as compared to MADE (Table 5). The importance of MADE giant sea salt is probably limited because the main emission regions of sea salt coincide with rainy regions such that most particles are immediately removed by impaction scavenging.

In contrast to sim simulations, the Passive M7 dust burden is decreased by about $80 \%$ in comparison to MADE due to increased dry deposition of the wider coarse mode and because the M7 dust burden has no contribution from the giant mode. The additional MADE dust leads to a strongly enhanced difference between MADE and M7 in the height of the coarse/giant mode peak in the size distribution (not shown) that otherwise remains qualitatively similar to that from the simSIG simulation (Fig. 5, black).

Differences in BC burden remain similar to the sim simulation (Table 5) as does the BC size distribution (not shown, but see Fig. 5). Similar to SIA, SOA and unspeciated aerosol from MADE are considered as part of an organic aerosol (OA) class. For M7, OA is identical to POA. SOA and unspeciated aerosols enhance the MADE OA burden to a $40 \%$ increased value as compared to M7 (Table 5). The OA size distribution (not shown) is qualitatively similar to that of POA from the sim simulation (Fig. 5).

\subsection{Radiative properties}

Figure 9 compares $550 \mathrm{~nm}$ AOD (aerosol optical depth) for the Passive simulations of MADE and M7. Comparing the pattern of AOD to the species burden in Fig. 3 shows that it is dominated by dust over Africa and the Mediterranean 
Table 7. $\mathrm{SO}_{4}$ surface concentrations in $\mu \mathrm{g} \mathrm{m}^{-3}$ for simulations according to Table 4. Values are horizontal averages over continental Europe.

\begin{tabular}{lrrr}
\hline & $\operatorname{sim}$ & $\operatorname{sim} \mathrm{AQ}$ & $\operatorname{sim} C L$ \\
\hline M7 & 0.23 & 1.66 & 1.65 \\
MADE & 0.27 & - & - \\
\hline
\end{tabular}

region. Over continental Europe and the Atlantic part of the domain, AOD is controlled by anthropogenic aerosols and sea salt. MADE AOD is $20 \%$ enlarged as compared to M7 in the dust-dominated part of the domain and about $100 \%$ enhanced in the rest of the domain (Table 5). In the regions of strongest flow (Fig. 2), differences of up to $200 \%$ occur (Fig. 9). The increased MADE AOD can be attributed to the additional modes and species of MADE, i.e., the giant dust mode, nitrate, ammonium, SOA and unspeciated aerosol. The AOD difference pattern is matched by the difference pattern of the total wet aerosol burden in the accumulation and coarse-mode size ranges (Fig. 9), which dominate the radiative effect because particles sizes correspond to the considered wavelength of $550 \mathrm{~nm}$. The difference pattern between MADE and M7 accumulation and coarse-mode soot does not correspond to the AOD differences pattern (not shown) and confirms that differences are caused by the additional scattering of MADE species and not by the differences in the distributions of absorbing soot in the Aitken and accumulation modes in MADE and M7 (Fig. 5).

Differences in aerosol radiative properties between MADE and M7 are dominated by differences in burden arising from the structural differences and not by differences in the parameterization of optical properties (Sect. 2.3). An estimate of the latter can be obtained from the sim simulation: for this setup, dust burden and size distribution are identical for MADE and M7, and dust is the only aerosol species over Africa in the lower-left quadrant of the domain (Figs. 3 and 5). An $18 \%$ increase in M7 AOD as compared to MADE in this region is thus caused by differences in the parameterization of aerosol optical properties alone. The decreased M7 AOD for the Passive simulation (Fig. 9) illustrates that this parameterization effect is less important than the structural effect of the additional MADE giant dust mode.

\subsection{Droplet-activation properties}

MADE produces $100 \%$ more CCN than M7 (Fig. 10, Table 5). The number distribution of soluble aerosols depicted in Fig. 11a illustrates that the increase in MADE CCN corresponds to an increased number of MADE aerosol particles in the Aitken mode size range that are large enough for activation as measured by a threshold radius of $35 \mathrm{~nm}$ based on the empirical activation parameterization by Lin and Leaitch (1997). MADE, on the one hand, features more particles in

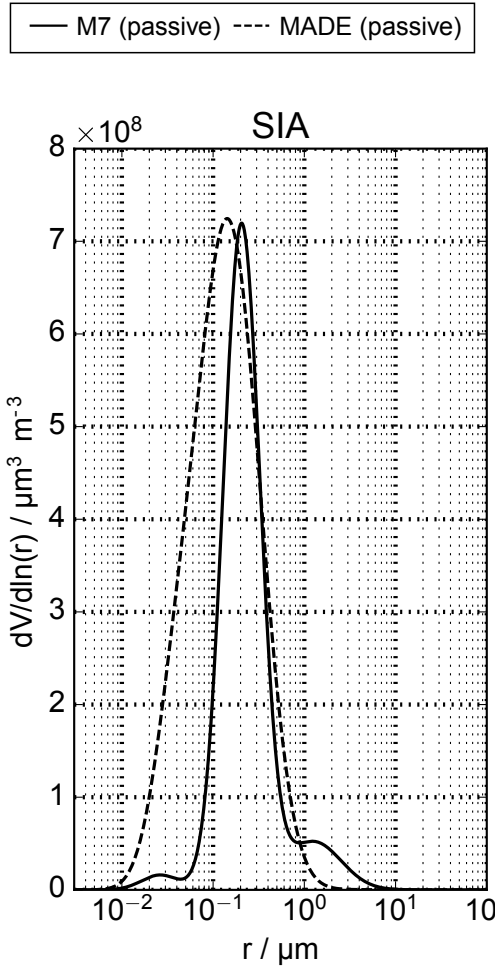

Figure 7. Domain-averaged volume distributions of SIA for default setups. This figure corresponds to $\mathrm{SO}_{4}$ in Fig. 5 but shows SIA for the Passive simulations. SIA corresponds to $\mathrm{SO}_{4}$ for $\mathrm{M} 7$ and additionally includes $\mathrm{NO}_{3}$ and $\mathrm{NH}_{4}$ for MADE.

the Aitken size range due to additional emissions of unspeciated $\mathrm{PM}_{2.5}$ particles that are not considered in M7. On the other hand, MADE Aitken mode particles are larger due to additional coating from SOA, nitrate and ammonium. Note that aqueous-phase-formed M7 sulfate cannot compensate for these species because it is predominantly assigned to accumulation mode particles, which are already large enough to be activated.

Figure 10 illustrates the situation for liquid clouds. Relative changes are comparable in mixed-phase clouds (Table 5), while absolute $\mathrm{CCN}$ numbers are about $40 \%$ lower than in liquid clouds (not shown) due to a general decrease in aerosol number concentration with height. Also note the $\mathrm{CCN}$ predicted in the absence of soluble Aitken and accumulation mode particles in the lower-right quadrant of the domain (Fig. 3): these result from adsorption activation of hydrophilic dust.

\subsection{Ice-nucleation properties}

Dust and soot are considered as ice-nucleation-active species in our simulations (Sect. 2.4). Dust has a much higher icenucleation potential so that it dominates ice nucleation when present. This is the case over Africa and the Mediterranean 

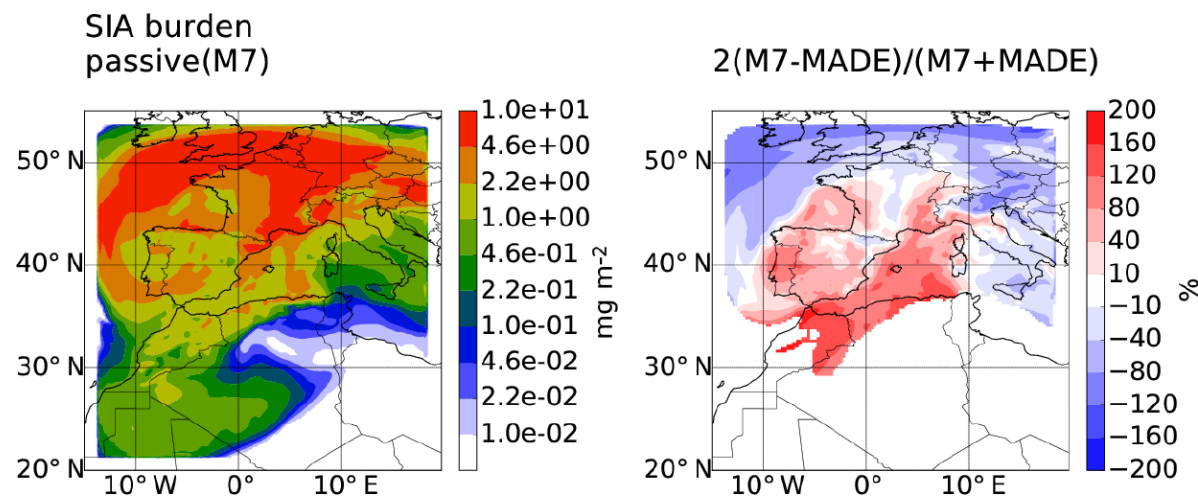

Figure 8. SIA burden for default setups. This figure corresponds to $\mathrm{SO}_{4}$ in Fig. 3 but shows SIA for the Passive simulations. SIA corresponds to $\mathrm{SO}_{4}$ for $\mathrm{M} 7$ and additionally includes $\mathrm{NO}_{3}$ and $\mathrm{NH}_{4}$ for MADE.
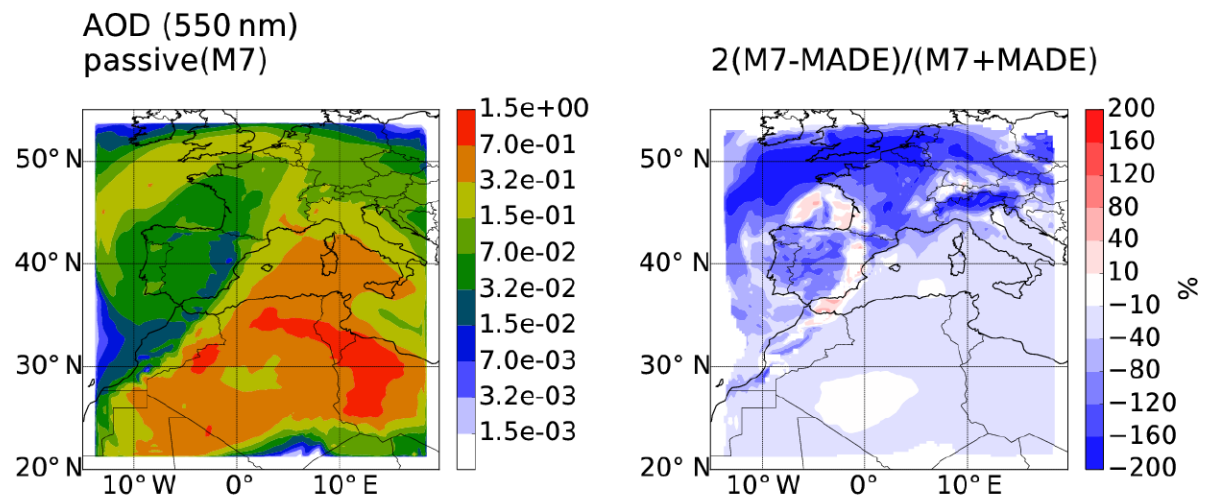

Accumulation and coarse-mode burden (wet) passive(M7)
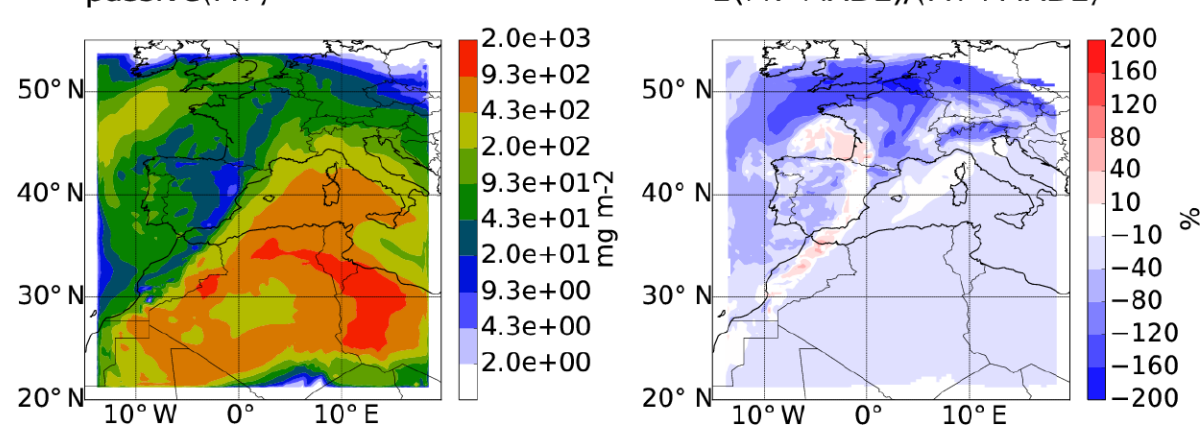

Figure 9. Aerosol optical properties. Aerosol optical depth at a wavelength of $550 \mathrm{~nm}$ (top row) and total wet aerosol burden in accumulation and coarse modes (bottom row) resulting from M7 (left column) and MADE (percentage-difference plots in the right column) aerosol for the Passive simulation. See Fig. 3 for plot details.

Sea (Fig. 3). Soot determines ice nucleation in the Atlantic part of the domain that is not affected by the dust outbreak.

\subsubsection{Dust-dominated ice nucleation}

As illustrated by the aerosol-surface distribution of dust in mixed-phase and ice clouds in Fig. 11b, the average surface of MADE dust particles available for ice nucleation is enhanced as compared to M7. Reasons for this increase are the MADE-only giant dust mode and increased dry deposition of dust from the M7 coarse mode due to its larger $\sigma$ (Sect. 4.1.2). At comparable number concentrations, the ice-nucleation potential increases with the average surface of particles (Phillips et al., 2008) such that INP concentrations tend to be increased for MADE as compared to M7 in clouds in dusty regions (Figs. 12, 13, Table 8).

In mixed-phase clouds (Fig. 12), M7 INPs are reduced by about $30 \%$ as compared to MADE for the Phillips and 
Table 8. Horizontal averages of relative differences $\Delta=2(\mathrm{M} 7-\mathrm{MADE}) /(\mathrm{M} 7+\mathrm{MADE})$ between MADE and M7 ice-nucleation properties in percent for Passive simulations with the Ullrich and Phillips ice-nucleation parameterizations. If not indicated otherwise domain averages are given. Values are based on vertically averaged concentrations and correspond to Figs. 12 and 13.

\begin{tabular}{lrr}
\hline & Ullrich & Phillips \\
\hline INPs in mixed-phase clouds (domain average) & -192 & -30 \\
INPs in mixed-phase clouds (average over Atlantic) & -190 & -18 \\
INPs in mixed-phase clouds (average over Mediterranean Sea) & 130 & -78 \\
\hline INPs in ice clouds (average over Atlantic) & -0 & -18 \\
INPs in ice clouds (average over Mediterranean Sea) & -0 & -24 \\
INPs in ice clouds (average over Africa) & -178 & -40 \\
Frozen solution droplet number (average over Atlantic) & -52 \\
INP + frozen solution droplet number (domain average where T<235 K) & -152 \\
\hline Solution droplet number in ice clouds (average over Atlantic) & \\
\hline
\end{tabular}

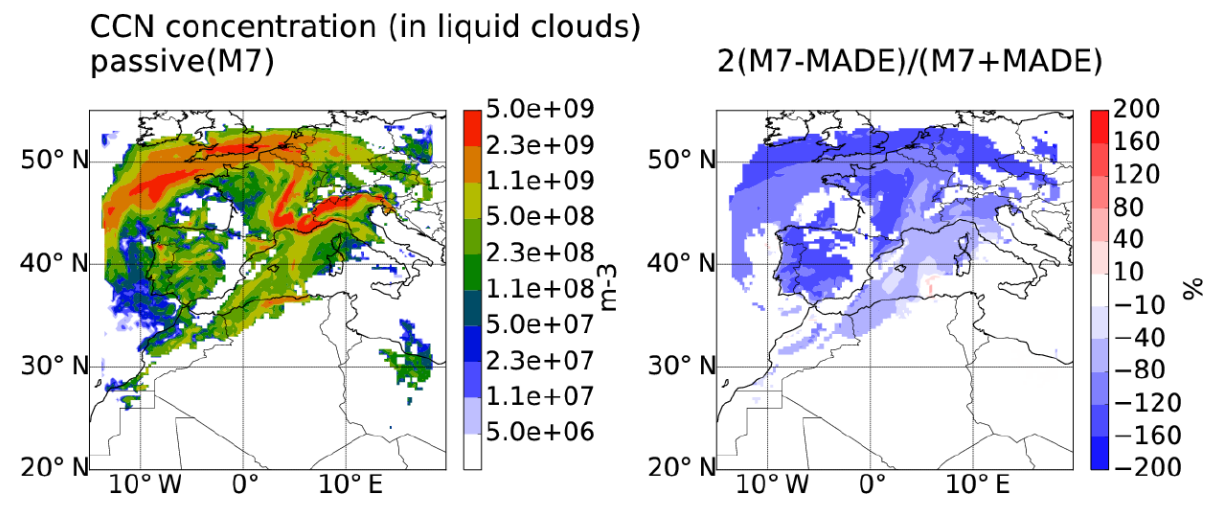

Figure 10. Liquid-cloud CCN concentrations derived from aerosol compositions predicted by M7 (left) and MADE (percentage-difference plot on the right) for Passive simulations. Contours show vertical averages of concentrations in grid boxes that contain liquid-phase but no ice-phase cloud water.

by more than $180 \%$ for the Ullrich parameterization. The strong difference for the Ullrich as compared to the Phillips parameterization is a result of a similarly dramatic difference in ice-nucleation-active dust, occurring because all MADE dust but only coated M7 dust is considered for the Ullrich ice-nucleation parameterization in mixed-phase clouds (the Phillips parameterization is based on total dust in both cases (Table 3); Fig. 11b is thus only relevant for the Phillips parameterization, and the corresponding distribution for the Ullrich parameterization is not shown). As the dominance of aqueous-phase sulfate production in M7 strongly restricts condensation and coating, most M7 dust remains uncoated: in the Mediterranean region about $10 \%$ is coated and over the Atlantic values up to $100 \%$ are reached. The number concentration of INPs is thus strongly constrained by the coating efficiency of dust, which depends on the aerosol model and its specific assumptions.

In dust-dominated ice clouds, we distinguish between two regions: the high dust concentrations in the southern part of the domain prevent supersaturations high enough for homogeneous freezing of solution droplets such that ice nucleation proceeds purely heterogeneously as indicated by the absence of frozen solution droplets in Fig. 13. For ice clouds over the Mediterranean Sea, dust concentrations are not large enough to prevent homogeneous freezing completely such that heterogeneous nucleation and homogeneous freezing compete. Due to inefficient coating, the surface distributions of uncoated dust, which is relevant for the Ullrich parameterization, is practically identical to that of total dust, which is relevant for the Phillips parameterization. Differences in Phillips and Ullrich INPs are thus both caused by practically identical differences in ice-nucleation-active dust between MADE and M7. Surprisingly, Phillips INPs are reduced by $20 \%$ for M7 as compared to MADE, and Ullrich INPs are reduced by less than $2 \%$ (Table 8 ) in both regions. This on the one hand points toward very different relative sensitivities of the Phillips as compared to the Ullrich parameterization. On the other hand, the difference might be influenced by the total INP concentration that the calculation of percentage changes is based on: the Ullrich parameterization results in absolute INP concentrations that are about 2 orders of magnitude higher than for the Phillips parameterization. Similarly dra- 
(a) (b)

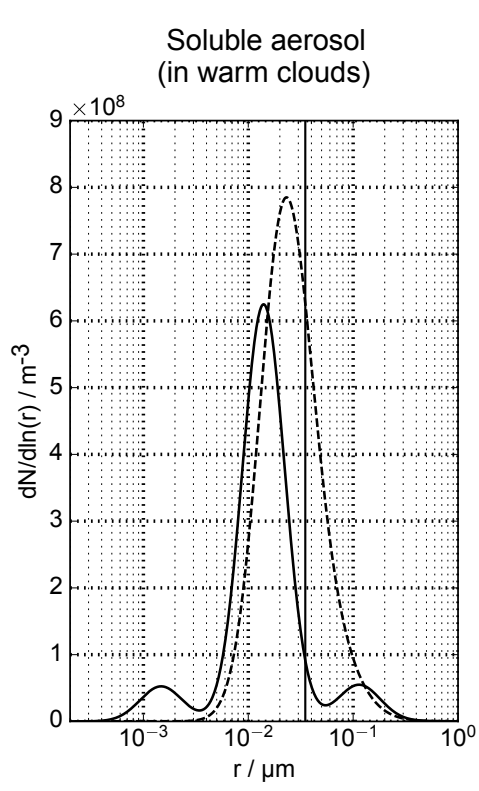

(c)

(d)

Total DU

(in mixed- and ice-phase clouds)
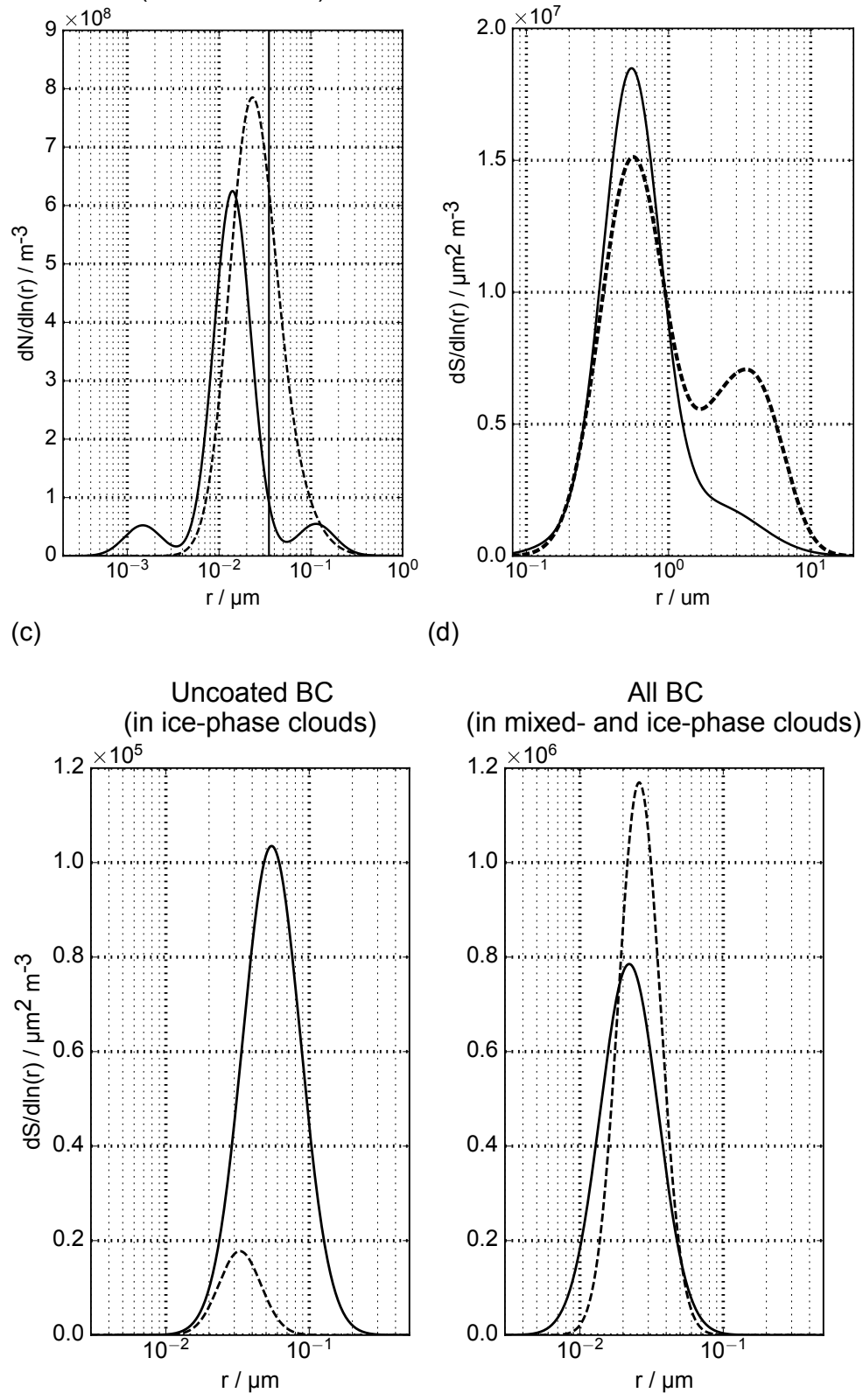

All BC

(in mixed- and ice-phase clouds)

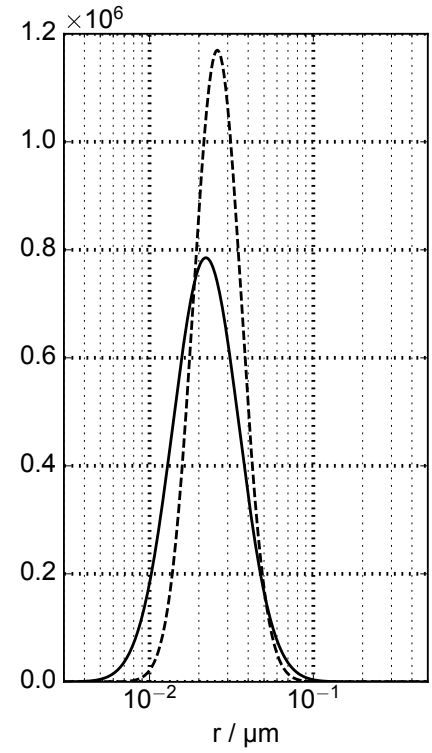

Figure 11. Size distributions of cloud-active aerosol for the Passive simulation using MADE and M7. Shown are the CCN-relevant number distribution of soluble aerosol in liquid clouds (a) as well as surface distributions of dust (b) and uncoated (c) and total soot (d) in the cloud regimes where these species serve as INPs (Table 3).

matic differences between the Phillips parameterization and an earlier version of the Ullrich parameterization have been discussed by Niemand et al. (2012) for mixed-phase clouds. As a consequence of the low absolute INP concentrations, the Phillips parameterization results in homogeneous freezing being the dominant ice-nucleation mechanism over the
Mediterranean Sea, while a competition between homogeneous and heterogeneous freezing occurs for the Ullrich parameterization. 

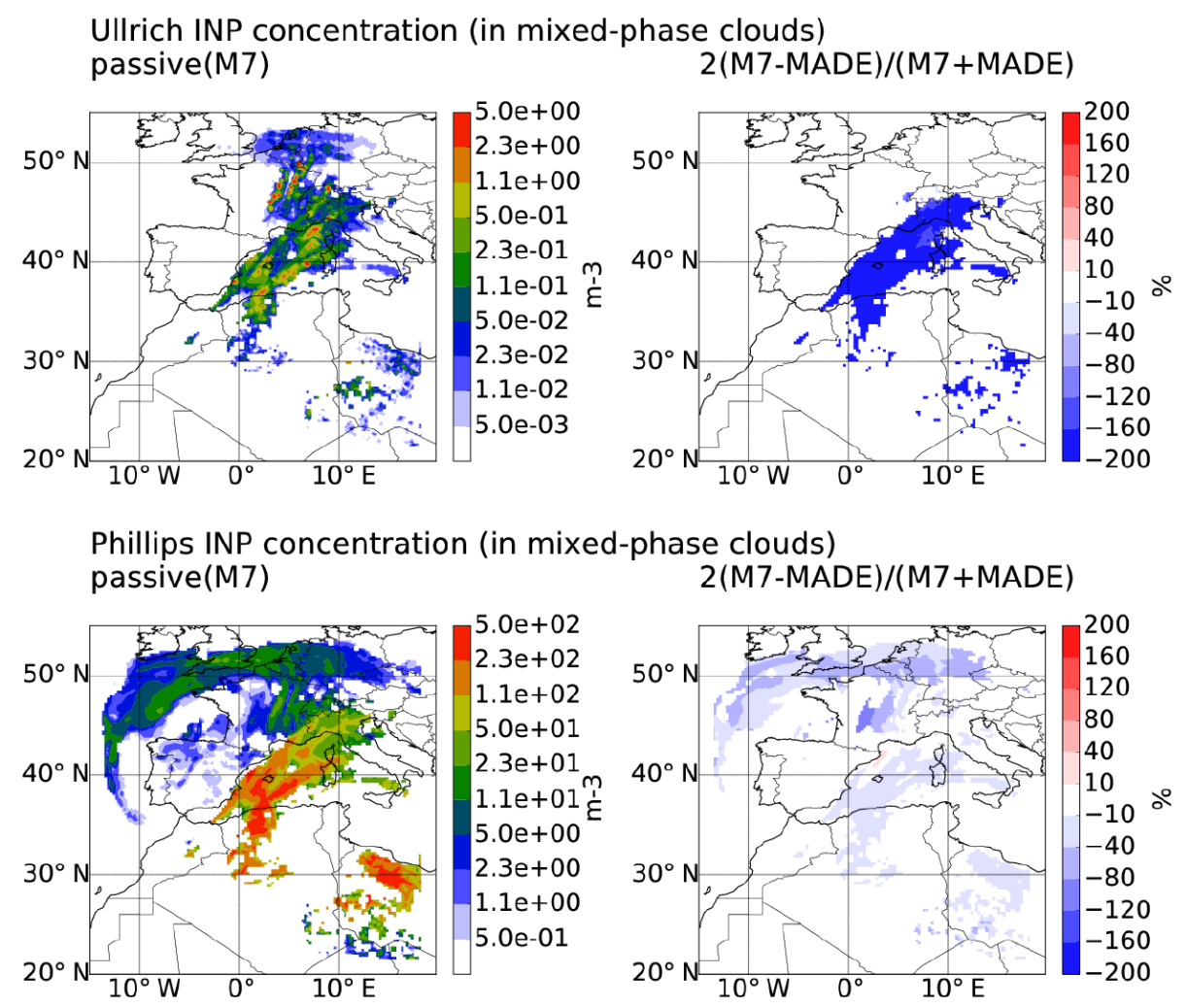

Figure 12. Mixed-phase INP concentrations derived from aerosol compositions predicted by M7 (left column) and MADE (relativedifference plots in the right column) using the Ullrich (first row) and Phillips (second row) parameterizations for Passive simulations. See Fig. 3 for plot details. Contours show vertical averages of concentrations in grid boxes that contain both ice- and liquid-phase cloud water.

\subsubsection{Soot-dominated ice nucleation}

In the Atlantic part of the domain, soot is the dominant source of INPs. The Ullrich parameterization does not consider soot as mixed-phase INPs such that mixed-phase Ullrich INPs are absent over the Atlantic (Fig. 12). For the Phillips parameterization, INPs are $34 \%$ increased for MADE as compared to M7. This MADE increase corresponds to an increase in the average surface of MADE soot in comparison to M7 (Fig. 11d). The differences in surface distribution between MADE and M7 are probably a consequence of the distinction between mixed aerosol (modes if and jf in Fig. 1, Table 1) and coated soot (modes ic, jc) in MADE, while M7 features only a single type of mixed mode (modes ks, as, cs): as discussed for sea salt in Sect. 4, M7 BC mass is distributed to the large number of all mixed particles, which is interpreted as every mixed particle having a soot core with a smaller size as compared to soot particles in the insoluble Aitken mode.

Soot-dominated ice nucleation in ice clouds according to the Ullrich parameterization results in a competition between heterogeneous and homogeneous freezing and thus corresponds to the situation of dust over the Mediterranean Sea discussed previously. Due to this competition, differences in the number concentrations of INPs between MADE and M7 control those of frozen solution droplets for the Ullrich pa- rameterization. Ullrich INPs are more than $120 \%$ increased for M7 as compared to MADE. This can be attributed to a reduced efficiency of $\mathrm{BC}$ coating for $\mathrm{M} 7$ in comparison to MADE as illustrated by the surface distributions of uncoated $\mathrm{BC}$ in Fig. 11c. The less efficient coating of M7 BC has two reasons: on the one hand, the SIA burden over the Atlantic is $40 \%$ smaller for M7 than for MADE due to MADE nitrate and ammonium. On the other hand, M7 sulfate is primarily produced via aqueous-phase chemistry, which prevents condensation as compared to the gas-phase production pathway of MADE. The increase in M7 Ullrich INPs as compared to MADE shifts the competition between homogeneous and heterogeneous nucleation towards heterogeneous nucleation and leads to a $180 \%$ decrease in frozen solution droplets. This mechanisms corresponds to a negative Twomey effect (Kärcher and Lohmann, 2003) with M7 corresponding to polluted and MADE to clean conditions.

For the Phillips parameterization, total INP concentrations are reduced as compared to the Ullrich parameterization such that homogeneous nucleation is the dominant freezing process in the Atlantic part of the domain for this parameterization (Fig. 13). Differences between MADE and M7 in terms of INP and frozen solution droplet number concentrations can thus be analyzed separately. A $40 \%$ higher abundance of frozen droplets in MADE as compared to M7 reflects dif- 


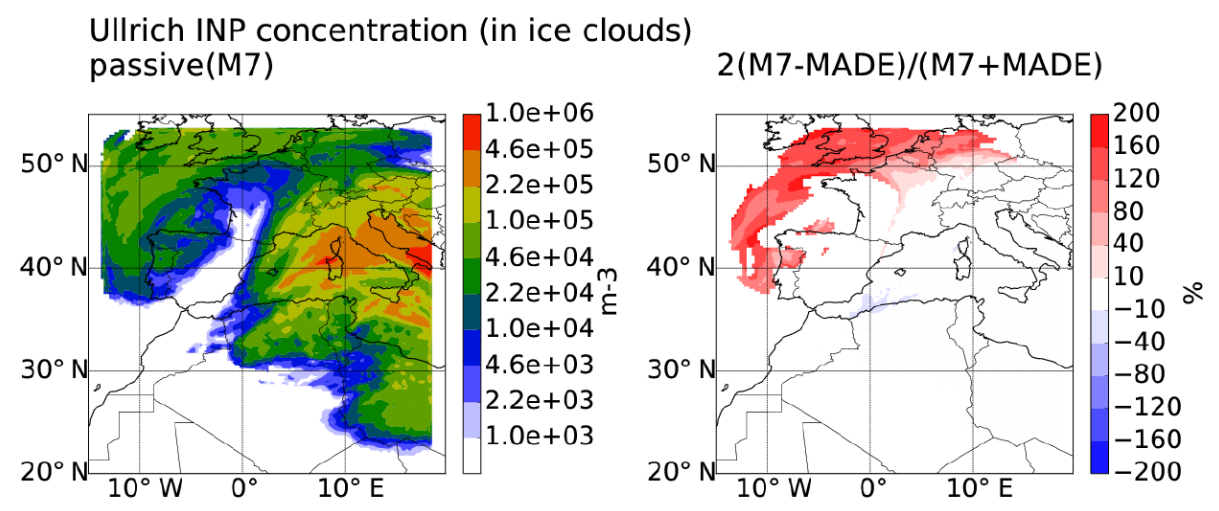

Number concentration of frozen solution droplets (Ullrich) passive(M7)

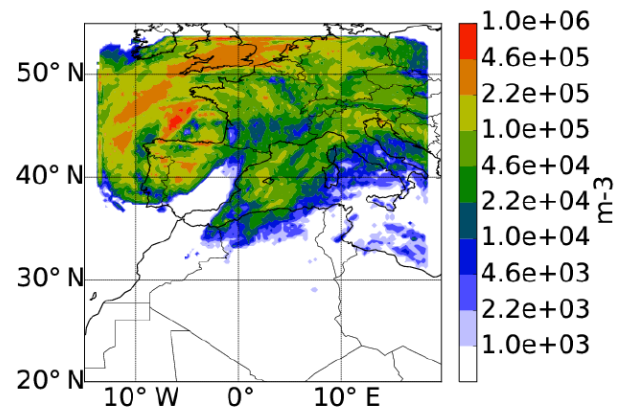

2(M7-MADE)/(M7+MADE)

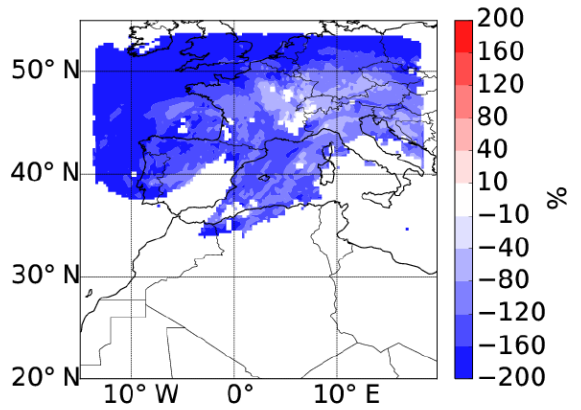

Phillips INP concentration (in ice clouds) passive(M7)

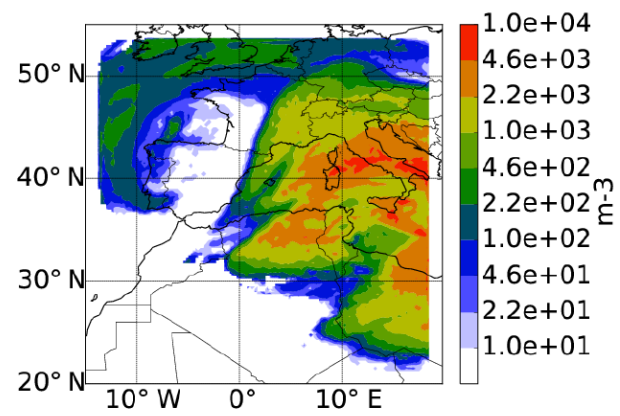

2(M7-MADE)/(M7+MADE)

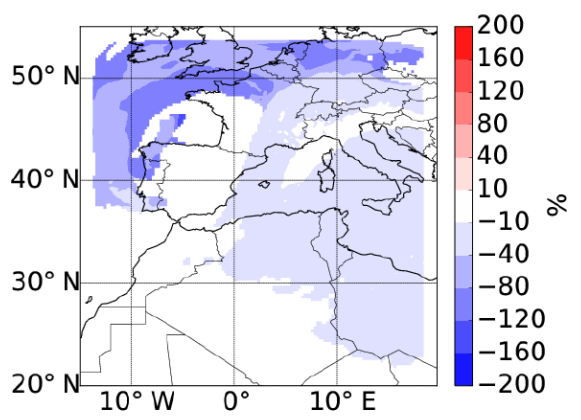

Number concentration of frozen solution droplets (Phillips) passive(M7)
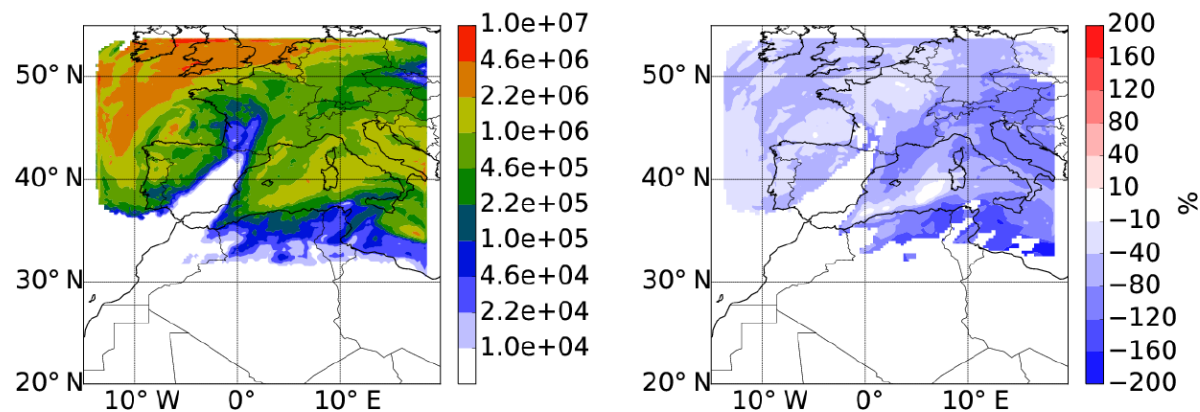

Figure 13. INP and frozen solution droplet concentrations in ice clouds derived from aerosol compositions predicted by M7 (left column) and MADE (relative-difference plots in the right column) using the Ullrich (first and second row) and the Phillips (third and last row) icenucleation parameterizations. Contours show vertical averages of concentrations in grid boxes that contain ice- but no liquid-phase cloud water. See Fig. 3 for plot details. 
ferences in the availability of solution droplets for freezing: MADE features a larger number of solution droplets than M7 $(+160 \%$, Table 8$)$ because freshly nucleated particles in the MADE Aitken mode are considered for homogeneous nucleation, while the corresponding particles in the M7 nucleation mode are excluded (Table 3). Differences in Phillips INPs and the corresponding soot distributions between MADE and M7 qualitatively follow the mixed-phase case with about $80 \%$ more MADE than M7 INPs (Table 8).

\subsubsection{Comparison of default combinations}

The standard version of COSMO-ART applies the Phillips ice-nucleation parameterization, while the Ullrich parameterization is more suitable for M7 to make use of the simulated difference between coated and uncoated dust. The discussion above shows that the differences between icenucleation parameterizations, as drastically illustrated by the absolute number of INPs in ice clouds in dust-dominated regions, and in the coupling of the ice-nucleation parameterization to the aerosol scheme, i.e., the consideration of coated vs. uncoated dust and the selection of modes participating in homogeneous freezing, mask the differences between the aerosol schemes. As a consequence, differences between MADE Phillips and M7 Ullrich are dominated both by differences in the ice-nucleation parameterization and its coupling to the aerosol scheme.

\subsection{Buffering effect of cloud microphysics}

While the optical properties of aerosols directly influence radiation, their cloud-forming properties as quantified by $\mathrm{CCN}$ and INPs can affect radiation and precipitation only indirectly via their influence on cloud droplet and ice crystal number concentration. In simulations with aerosol-cloud interactions (Coupled simulations in Table 4), CCN and INPs correspond to the activation and ice-nucleation rate and thus to sources of droplet and crystal number concentration. In addition, droplet and crystal number concentrations are subject to cloud microphysical processes, including number sinks like collision-coalescence, riming and aggregation. These processes modify the effect of aerosol differences on droplet and crystal number concentration as compared to their effect on CCN and INPs. The mediating effect of cloud microphysics on relative changes $\Delta N / N$ in a hydrometeor number concentration $N$ that result from a relative change $\Delta \mathrm{CN} / \mathrm{CN}$ in the concentration of a cloud nuclei can be quantified by a relative sensitivity or susceptibility (McComiskey et al., 2009; Glassmeier and Lohmann, 2016):

$s:=\frac{\mathrm{d} \ln N}{\mathrm{~d} \ln \mathrm{CN}} \approx \frac{\Delta N / N}{\Delta \mathrm{CN} / \mathrm{CN}}$.

This universal equation quantifies liquid-phase (ice-phase) aerosol-cloud interactions when applying them to the droplet (ice crystal) number concentration $N_{\text {droplet }}\left(N_{\text {crystal }}\right)$ and
CCN (INPs) by substituting $N=N_{\text {droplet }}\left(N=N_{\text {crystal }}\right)$ and $\mathrm{CN}=\mathrm{CCN}(\mathrm{CN}=\mathrm{INP})$. These susceptibilities can be determined from double logarithmic plots of $\ln N$ as a function of $\ln \mathrm{CN}$. The susceptibility is a characteristic of the cloud microphysics scheme, and its value will be different for different cloud regimes and states. To get a sampling of these regimes and states that is representative of the studied case, we make use of the horizontal variability in the domain and use spatially resolved data from simulations with twomoment microphysics (Coupled simulations in Table 4), temporally and vertically averaged over cloudy grid points in the same way as the data depicted in the contour plots of Figs. 10 to 13 . As the cloud microphysics scheme that mediates the relationship between $\mathrm{CN}$ and $N$ is the same for MADE and M7, we combine data points from simulations with both schemes. The resulting fits are shown in Fig. 14, for warm, mixed-phase and cirrus clouds.

Cloud droplet number concentrations are significantly lower than predicted concentrations of CCN (Fig. 14a). On the one hand, this arises because our CCN diagnostic does not take into account the competition of different droplets for water vapor, which is considered in the nucleation rate computed in the Coupled simulations (Sects. 2.4, 3). On the other hand, growth by collision-coalescence as a droplet sink plays a role in modifying $\mathrm{N}$ (a similar argument is given by McComiskey et al., 2009): colors encode the average mass of cloud droplets and rain drops. Small values correspond to recently formed clouds where droplets are too small for efficient collisions. The corresponding data points thus lie closest to the 1:1 line. Large average mass corresponds to raining clouds with efficient collisions and strongly reduced drop number concentrations. The coefficient of determination may be interpreted such that $70 \%$ of the relative variability in warm cloud droplet number can be explained by relative variability in the available CCN. Differences in the microphysical state of the cloud, for which hydrometeor size is a proxy, partly account for the unexplained $30 \%$ of the variance as indicated by the systematic color pattern.

Ice crystal number concentrations are always higher than the number concentration of INPs in mixed-phase clouds (Fig. 14b). This can be attributed to ice crystal sources other than the heterogeneous freezing of cloud droplets. In our model, these are the freezing of rain drops, ice multiplication by rime splintering and the sedimentation of ice crystals from aloft. These INP-independent ice crystal source processes can also explain that crystal numbers are only weakly dependent on INPs, which account for only $20 \%$ of variance. An additional factor is crystal sedimentation, which provides a number sink that has no analog in warm clouds because cloud droplet sedimentation is negligible. For a given INP concentration, crystal concentration instead increases with increasing glaciation as defined by the fraction of frozen to total cloud water. Like hydrometeor size in the warm case, this glaciation fraction might be considered a proxy for the state of the cloud. 
(a)

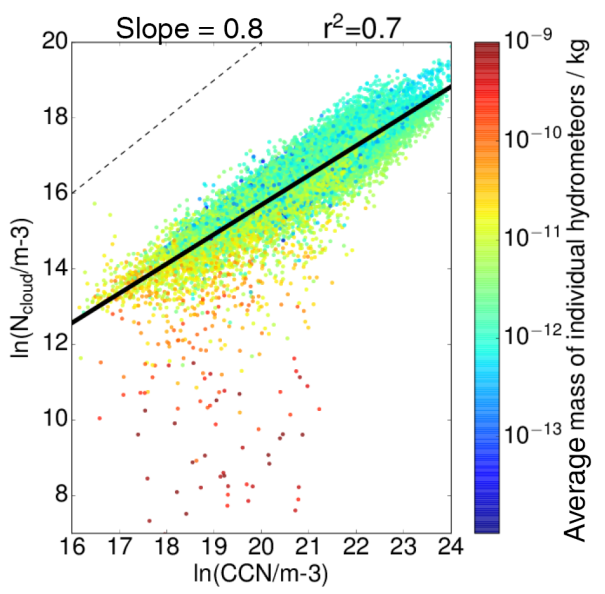

(b)

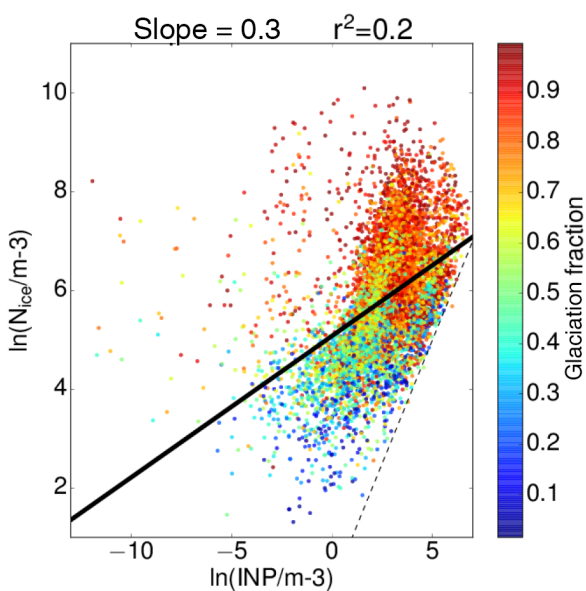

(c)

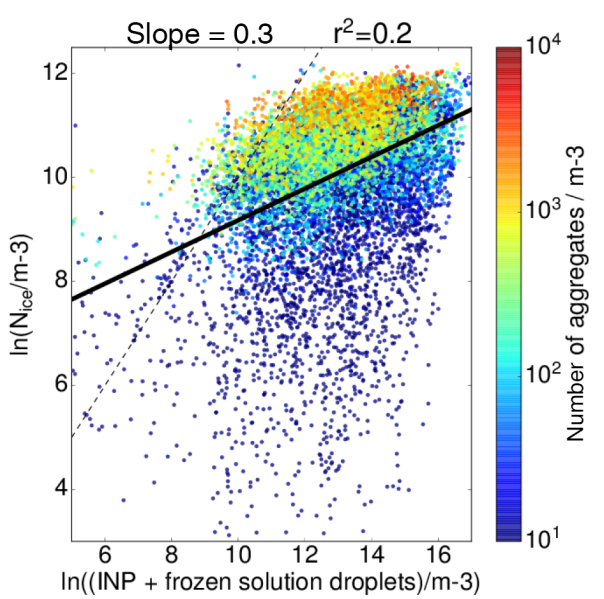

Figure 14. Relationship between CCN/INP and cloud droplet number concentration $N_{\mathrm{cl}}$ and ice crystal number concentration $N_{\mathrm{ci}}$. The figures show double logarithmic scatterplots of the cloud droplet number concentration $N_{\mathrm{cl}}$ as a function of CCN concentration in liquid clouds (a) and the ice crystal number concentration $N_{\mathrm{ci}}$ as a function of INP concentration in mixed-phase clouds (b) and as a function of the combined concentration of INPs + frozen solution droplets in cirrus clouds (c). Warm and mixed-phase clouds are defined as in Figs. 10 and 12; cirrus clouds are restricted to regions with competition of heterogeneous and homogeneous freezing as indicated by nonvanishing numbers of both INP and solution droplets. Data points represent temporally and vertically averaged values from Coupled simulations with the Phillips ice-nucleation parameterization at every grid point (see text for details). Only every fifth data point used for the fit is displayed. Solid black lines illustrate least-square fits with slope and coefficient of determination $r^{2}$ as indicated in plot titles. All fits are significant. Black dashes indicate 1:1 lines. Colors denote the mass of individual hydrometeors, averaged over all cloud droplets and rain drops (a), the glaciation fraction, i.e., the ratio of frozen to total cloud water (b), and the number of ice crystal aggregates (c).

In cirrus clouds, ice crystal number concentrations tend to be smaller than the sum of INP and frozen solution droplets (Fig. 14c), likely as a result of sedimentation as an ice crystal sink. Sedimentation is most effective for large hydrometeors in the snow category of the microphysics scheme that result from the aggregation of individual ice crystals. Although aggregation is not very efficient at the low temperatures of cirrus clouds, the degree of aggregation seems a possible proxy for the microphysical cloud state: the color-coding based on the number of aggregates in Fig. 14c can explain variance in addition to differences in the number concentration of INPs and frozen droplets, which explain $20 \%$. Data points above the $1: 1$ line are probably related to the homogeneous freezing of cloud droplets that are advected to regions with temperatures colder than $235 \mathrm{~K}$. This freezing of cloud droplets has to be distinguished from the homogeneous freezing of solution droplets predicted by the ice-nucleation parameterization. Homogeneous freezing of cloud droplets is restricted to cirrus or ice clouds of liquid origin, e.g., outflows from convective clouds or high-reaching tops of nimbostratus clouds. It seems that this cirrus regime contributes to the variability of the relationship between INPs and frozen solution droplets and ice crystal number concentrations in the regime of low crystal concentrations. 
Table 9. Relative difference in cloud droplet and ice crystal number $N$ between MADE and M7 as predicted according to Eq. (2) from fitted susceptibilities $s$ and domain-averaged values of relative differences in cloud nuclei $\Delta \mathrm{CN} / \mathrm{CN}$ from the Passive simulation (Table 8).

\begin{tabular}{lrrr}
\hline Cloud & $\Delta \mathrm{CN} / \mathrm{CN}$ & $s$ & $\Delta N / N$ \\
\hline Liquid & $-108 \%$ & 0.8 & $-86 \%$ \\
Mixed phase & $-30 \%$ & 0.3 & $-9 \%$ \\
Cirrus & $-52 \%$ & 0.3 & $-17 \%$ \\
\hline
\end{tabular}

Our discussion of Fig. 14 illustrates that a detailed understanding of the influence of cloud microphysics on the coupling between parameterized cloud nuclei and the number concentration of cloud droplets and ice crystals would require a more detailed analysis, including a separation of cloud regimes and microphysical cloud states. This is beyond the scope of the current study. By rearranging Eq. (1) according to

$$
\frac{\Delta N}{N} \approx s \cdot \frac{\Delta \mathrm{CN}}{\mathrm{CN}}
$$

the values of the fitted slopes with $s<1$ nevertheless show that cloud microphysics dampens, or buffers, the effect of differences in the aerosol representation, i.e., MADE vs. M7, on $N$ as compared to $\mathrm{CN}$ : an aerosol signal in $\mathrm{CN}$ will overestimate the signal in $N$ and thus an effect on clouds (Table 9). The buffering effect on the ice phase is stronger than in liquid clouds. Nevertheless, Table 9 shows that the details of the chemistry and aerosol scheme have a nonvanishing effect on all three cloud types investigated.

Note that we prefer the susceptibility-based estimate over a direct comparison of $N$ for Coupled simulations with MADE and M7 because Coupled simulations do not have identical meteorologies for the different aerosol schemes. Differences in meteorology, specifically in supersaturation and temperature, influence differences in $\mathrm{CN}$ in addition to aerosol differences. Not taking this additional meteorological variability into account would result in an overestimation of $\Delta \mathrm{CN} / \mathrm{CN}$ and consequently of $\Delta N / N$.

\section{Conclusions}

We have coupled the M7 aerosol scheme (Vignati et al., 2004) and the computationally efficient sulfur chemistry of Feichter et al. (1996) with the regional aerosol and reactive trace gas model COSMO-ART with interactive meteorology (Vogel et al., 2009). While the M7 aerosol framework was designed for climate applications, the full gas-phase chemistry and the aerosol scheme MADE in COSMO-ART emerged from regional-scale air-quality applications. The availability of the two different descriptions of aerosol and aerosol-related chemistry within the same modeling frame- work allows for a detailed comparison and process-level understanding of their differences. As both aerosol schemes adopt a modal two-moment approach, this comparison reveals especially clearly the uncertainty in aerosol modeling arising from design and parameter choices within this framework. Here, we have compared the aerosol modules in a case study of a Saharan dust outbreak reaching Europe.

For this case, a sensitivity study with identical emissions and identical parameterizations of dry and wet deposition for both schemes shows the following sensitivities of simulated atmospheric aerosol burden, sorted in order of decreasing importance:

1. consideration of sulfate production by aqueous oxidation (140\% difference; Fig. 6, Table 5)

2. coarse-mode composition ( $120 \%$ difference, affecting the sulfate burden in Fig. 4)

3. modal standard deviation $(20-40 \%$ difference in dust/sea salt size distributions in Fig. 5)

4. accumulation and Aitken mode composition (10\% difference in POA and BC burden in Fig. 3)

5. oxidant fields for sulfate production ( $2 \%$ difference; Table 6).

The strong sensitivity of the aerosol burdens to sources is well recognized in the aerosol modeling community (Mann et al., 2014). Our example especially stresses that uncertainties are not limited to prescribed anthropogenic emissions but extend to parameterized aerosol sources like chemically derived sulfate (1). It needs to be pointed out, however, that the importance of aqueous oxidation displays a strong regional dependence as it depends on cloud cover and droplet $\mathrm{pH}$ values. Aerosol sink processes are similarly sensitive and strongly increased for large internally mixed aerosol particles (2). Modal standard deviation is an inevitable but is an important parameter of a two-moment scheme, especially for the dry deposition and impaction scavenging of coarse-mode particles (3). Aitken and accumulation mode aerosol mass is less affected by dry deposition and impaction scavenging such that their composition and standard deviation is less important in determining aerosol burden (4).

In contrast to these sensitivities, we find that climatological oxidant fields perform as well as hourly values in this example (5). In the investigated case, emissions of $\mathrm{SO}_{2}$ are largely restricted to cloudy regions such that sulfate is predominantly produced by aqueous-phase chemistry. Also, the effect of opposing deviations of the climatological oxidant fields from the hourly values compensate for their effect on the overall aqueous-phase reaction rate. Although our result is not generally applicable, it hints at low sensitivities of the sulfate burden to oxidant fields in at least some cases and confirms the validity of a constant-oxidant-field approach for efficient aerosol-related chemistry. It has to be explored in 
future research whether extensions of the approach to other secondary aerosols, namely SOA, nitrate and ammonium, can provide a sufficiently accurate and computationally feasible way to account for these species in climate applications.

A comparison of both aerosol schemes in their default setups is strongly influenced by those aerosol species that are only considered by MADE, namely nitrate, ammonium, SOA and unspeciated aerosol, and by the likewise MADE-specific giant modes, especially for dust. We find that the additional sulfate produced by the M7 aqueous chemistry partially compensates for the additional nitrate and ammonium aerosol specific to MADE.

The additional MADE species play a large role for the sensitivities of $\mathrm{CCN}$ and optical properties to the aerosol scheme. MADE features $40 \%$ (mixed-phase clouds) to $100 \%$ (liquid clouds) higher CCN concentrations than M7 due to MADE-specific soluble species, i.e., nitrate, ammonium, SOA and unspeciated aerosol. M7-specific aqueousphase-derived sulfate mainly increases particles that are already $\mathrm{CCN}$-sized and hardly affects the $\mathrm{M} 7 \mathrm{CCN}$ concentration. MADE AOD is about $100 \%$ increased as compared to $\mathrm{M} 7$ in anthropogenically influenced regions. Over dustdominated African regions, MADE AOD is $20 \%$ larger than M7 AOD, partly due to the MADE-only giant dust mode. Differences in the parameterizations of aerosol optical properties between MADE and M7 are found to be less important than the differences in burden.

The INP potential of an aerosol depends on its surface area. For the Phillips ice-nucleation parameterization, which is independent of the mixing state and coating of an aerosol, we find that differences in dust and soot burden and surface area explain differences in INPs. For the Ullrich parameterization, which depends on the coating state of soot and dust, the abundance of secondary inorganic aerosol available for coating becomes more important in explaining differences in INP numbers than the burden and size of ice-nucleationactive species. In conditions where ice nucleation is dominated by homogeneous freezing of solution droplets, ice crystal concentrations are influenced by the number of soluble aerosol particles available for homogeneous freezing. As the total aerosol number is dominated by freshly nucleated particles, we find the minimum size of particles considered large enough to freeze homogeneously to be a relevant parameter. Large differences between the Phillips and Ullrich ice-nucleation parameterizations show, however, that uncertainties in parameterizing ice nucleation, in terms of the ice-nucleation spectrum as well as concerning the choice of inputs from the aerosol scheme, are more important than uncertainties in modeled aerosol number, amount and composition.

Applying a susceptibility-based approach, we find that cloud microphysics dampens the differences in $\mathrm{CCN}$ and INPs arising from differences between MADE and M7 aerosol microphysics along the line of clouds as buffered systems (Stevens and Feingold, 2009). The effect is especially pronounced for the ice phase. Nevertheless, both schemes result in significantly different cloud droplet and ice crystal number concentrations. Uncertainties in representing aerosol and aerosol processes thus carry over not only to the direct optical properties of aerosol but also to the representation of clouds. For a propagation of this signal to precipitation, however, further buffering effects are expected (Glassmeier and Lohmann, 2016).

In summary, differences between the two aerosol microphysics schemes and resulting differences in radiative properties and aerosol-cloud interactions originate mainly in different structural assumptions of the schemes, in particular concerning aerosol species, chemical reactions, modal composition and standard deviation, and inputs for the icenucleation parameterization. Resulting impacts on radiative properties and aerosol-cloud interactions are buffered: on the one hand by compensating for structural differences between additional sulfate from aqueous-phase chemistry for M7 and additional nitrate, SOA and unspeciated aerosol for MADE, on the other hand by sublinear relationships between aerosols and clouds.

We conclude that the new model version COSMO-ARTM7 simulates satisfying aerosol burdens in comparison to the established and observationally validated modeling framework COSMO-ART (Knote et al., 2011). Differences in burdens can be attributed to the choice of uncertain parameters, in particular modal standard deviation, and different structural assumptions in the form of missing species like SOA, nitrate and ammonium, and the choice of modes in terms of solubility and mixing state. This study provides the opportunity to discuss these choices in terms of the air-quality and climate objectives they are designed for. For climate applications, a computationally efficient aerosol scheme, such as M7, is needed that permits as realistic as possible a computation of radiative effects and aerosol-cloud interactions. As discussed earlier, simplified chemistry seems a viable option to save computational cost. In terms of aerosol-cloud interactions, the M7 approach to distinguish soluble from insoluble aerosol but to only consider one mixing state might be biased towards warm clouds. Ice nucleation not only depends on the mixing state of dust but also on an accurate representation of the dust surface. The latter is lost for internally mixed dust and soot. This raises the question of whether the representation of dust surfaces in $\mathrm{M} 7$ should be improved by following MADE in excluding dust from the mixed modes and adding a separate, coated dust mode. To keep the original number of modes and the corresponding computational costs the same, the uncoated accumulation and coarse dust modes could be replaced by a coated and an uncoated dust mode of intermediate size. When applying MADE for airquality applications, the chemical speciation as well as the abundance of individual aerosol species, precursor gases and pollutant gases such as tropospheric ozone are of great interest. For this purpose, as simplified a treatment of chemistry as is used in M7 is no longer justified and a far more com- 
plex treatment is needed. However, this study confirms that an aqueous-phase chemistry that is efficient enough for the standard setup (a detailed aqueous-phase chemistry and wetscavenging scheme for COSMO-ART has been developed by Knote and Brunner, 2013) may be a relevant objective for future model development.

Code availability. Model code is subject to licensing following http://www.cosmo-model.org/content/consortium/licencing.htm for COSMO-ART and additionally https://redmine.hammoz.ethz. ch/projects/hammoz/wiki/1_Licencing_conditions for COSMOART-M7. Licences are free of charge for research applications. They are available from the authors upon request.

Data availability. Simulation output is archived on ETH Zurich infrastructure and available from the authors upon request. 


\section{Appendix A: List of abbreviations and terms}

$\begin{array}{ll}\text { ai } & \text { M7 insoluble accumulation mode } \\ \text { AOD } & \text { aerosol optical depth } \\ \text { ART } & \text { Aersosol and Reactive Trace gases } \\ \text { as } & \text { M7 solute-containing accumulation mode } \\ \text { BC } & \text { black carbon (soot) } \\ \text { ca } & \text { MADE unspeciated anthropogenic coarse mode } \\ \text { CCN } & \text { cloud condensation nucleus/nuclei } \\ \text { ci } & \text { M7 insoluble coarse mode } \\ \text { COSMO } & \text { Consortium for Small-Scale Modelling } \\ \text { Coupled } & \text { see Table 4 } \\ \text { cs } & \text { M7 solute-containing coarse mode } \\ \text { da } & \text { MADE accumulation dust mode } \\ \text { db } & \text { MADE coarse dust mode } \\ \text { dc } & \text { MADE giant dust mode } \\ \text { DU } & \text { dust } \\ \text { ic } & \text { MADE soluble Aitken mode with soot core } \\ \text { if } & \text { MADE soluble Aitken mode without soot core } \\ \text { INP } & \text { ice nucleating particle } \\ \text { jc } & \text { MADE soluble accumulation mode with soot core } \\ \text { jf } & \text { MADE soluble accumulation mode without soot core } \\ \text { ki } & \text { M7 insoluble Aitken mode } \\ \text { ks } & \text { M7 solute-containing Aitken mode } \\ \text { M7 } & \text { Modal aerosol scheme with 7 modes } \\ \text { MADE } & \text { Modal Aerosol Dynamics model for Europe } \\ \text { ns } & \text { M7 nucleation mode } \\ \text { OA } & \text { organic aerosol } \\ \text { Passive } & \text { see Table 4 } \\ \text { PDF } & \text { probability density function } \\ \text { POA } & \text { primary organic aerosol } \\ \text { sa } & \text { MADE accumulation sea salt mode } \\ \text { sb } & \text { MADE coarse sea salt mode } \\ \text { sc } & \text { MADE giant sea salt mode } \\ \text { SIA } & \text { secondary inorganic aerosol } \\ \text { sim } & \text { see Table 4 } \\ \text { simSIG } & \text { see Table 4 } \\ \text { simAQ } & \text { see Table 4 } \\ \text { simCL } & \text { see Table 4 } \\ \text { so } & \text { MADE pure soot mode } \\ \text { SOA } & \text { secondary organic aerosol } \\ \text { SS } & \text { sea salt } \\ \text { TKE } & \text { turbulent kinetic energy } \\ & \end{array}$


Competing interests. BV is a co-editor of ACP. Other than this, the authors declare that they have no conflict of interest.

Acknowledgements. We thank Grazia Frontoso for isolating an M7 box model from ECHAM-HAM, Romy Ullrich for sharing the implementation of her ice-nucleation parameterization, and Ulrich Blahak and Axel Seifert for providing their cloud microphysics scheme. Max Bangert is gratefully acknowledged for his assistance, especially with the coupling of M7 to ART and the initial adaptation of the aerosol-cloud and aerosol-radiation interactions to M7. We also thank Isabel Kraut for her introduction to the application of KPP in COSMO-ART. Jianxiong Cheng and Olga Henneberg are acknowledged for first versions of wet chemistry and an M7-adapted impaction scavenging routine. We further thank Johann Feichter for clarifying some details of his chemistry scheme, Tanja Stanelle for discussions about the optical properties of dust in ART and Annette Miltenberger for her opinion on the choice of the simulated case. Isabelle Bey is acknowledged for her support in developing COSMO-ART-M7. We further thank two anonymous reviewers for their detailed and constructive comments on the paper. Franziska Glassmeier and Anna Possner were funded by the ETH-domain CCES project OPTIWARES (41-02).

Edited by: Hailong Wang

Reviewed by: two anonymous referees

\section{References}

Athanasopoulou, E., Vogel, H., Vogel, B., Tsimpidi, A. P., Pandis, S. N., Knote, C., and Fountoukis, C.: Modeling the meteorological and chemical effects of secondary organic aerosols during an EUCAARI campaign, Atmos. Chem. Phys., 13, 625-645, https://doi.org/10.5194/acp-13-625-2013, 2013.

Baer, M. and Nester, K.: Parametrization of trace gas dry deposition velocities for a regional mesoscale diffusion model, Ann. Geophys., 10, 912-923, https://doi.org/10.3390/atmos2030464, 1992.

Bangert, M., Kottmeier, C., Vogel, B., and Vogel, H.: Regional scale effects of the aerosol cloud interaction simulated with an online coupled comprehensive chemistry model, Atmos. Chem. Phys., 11, 4411-4423, https://doi.org/10.5194/acp-114411-2011, 2011.

Bangert, M., Nenes, A., Vogel, B., Vogel, H., Barahona, D., Karydis, V. A., Kumar, P., Kottmeier, C., and Blahak, U.: Saharan dust event impacts on cloud formation and radiation over Western Europe, Atmos. Chem. Phys., 12, 4045-4063, https://doi.org/10.5194/acp-12-4045-2012, 2012.

Bangert, M. J.: Interaction of Aerosol, Clouds, and Radiation on the Regional Scale, PhD thesis, KIT, 2012.

Barahona, D. and Nenes, A.: Parameterizing the competition between homogeneous and heterogeneous freezing in cirrus cloud formation - monodisperse ice nuclei, Atmos. Chem. Phys., 9, 369-381, https://doi.org/10.5194/acp-9-369-2009, 2009a.

Barahona, D. and Nenes, A.: Parameterizing the competition between homogeneous and heterogeneous freezing in ice cloud formation - polydisperse ice nuclei, Atmos. Chem. Phys., 9, 59335948, https://doi.org/10.5194/acp-9-5933-2009, 2009b.
Barahona, D., West, R. E. L., Stier, P., Romakkaniemi, S., Kokkola, H., and Nenes, A.: Comprehensively accounting for the effect of giant $\mathrm{CCN}$ in cloud activation parameterizations, Atmos. Chem. Phys., 10, 2467-2473, https://doi.org/10.5194/acp10-2467-2010, 2010.

Bartholomé, E. and Belward, A. S.: GLC2000: a new approach to global land cover mapping from Earth observation data, Int. J. Remote Sens., 26, 1959-1977, https://doi.org/10.1080/01431160412331291297, 2005.

Bigg, E. K.: The formation of atmospheric ice crystals by the freezing of droplets, Q. J. Roy. Meteor. Soc., 79, 510-519, https://doi.org/10.1002/qj.49707934207, 1953.

Binkowski, F. and Shankar, U.: The regional particulate matter model. 1. Model description and preliminary results, J. Geophys. Res.-Atmos., 100, 26191-26209, https://doi.org/10.1029/95JD02093, 1995.

Damian, V., Sandu, A., Damian, M., Potra, F., and Carmichael, G. R.: The kinetic preprocessor KPP - a software environment for solving chemical kinetics, Comput. Chem. Eng., 26, 15671579, 2002.

Emmons, L. K., Walters, S., Hess, P. G., Lamarque, J.-F., Pfister, G. G., Fillmore, D., Granier, C., Guenther, A., Kinnison, D., Laepple, T., Orlando, J., Tie, X., Tyndall, G., Wiedinmyer, C., Baughcum, S. L., and Kloster, S.: Description and evaluation of the Model for Ozone and Related chemical Tracers, version 4 (MOZART-4), Geosci. Model Dev., 3, 43-67, https://doi.org/10.5194/gmd-3-43-2010, 2010.

Feichter, J., Kjellström, E., Rodhe, H., Dentener, F., Lelieveld, J., and Roelofs, G.-J.: Simulation of the tropospheric sulfur cycle in a global climate model, Atmos. Environ., 30, 1693-1707, 1996.

Fountoukis, C. and Nenes, A.: Continued development of a cloud droplet formation parameterization for gobal climate models, J. Geophys. Res., 110, D11212, https://doi.org/10.1029/2004JD005591, 2005.

Fountoukis, C. and Nenes, A.: ISORROPIA II: a computationally efficient thermodynamic equilibrium model for $\mathrm{K}^{+}$ $\mathrm{Ca}^{2+}-\mathrm{Mg}^{2+}-\mathrm{NH}_{4}^{+}-\mathrm{Na}^{+}-\mathrm{SO}_{4}^{2-}-\mathrm{NO}_{3}^{-}-\mathrm{Cl}^{-}-\mathrm{H}_{2} \mathrm{O}$ aerosols, Atmos. Chem. Phys., 7, 4639-4659, https://doi.org/10.5194/acp-74639-2007, 2007.

Fountoukis, C., Racherla, P. N., Denier van der Gon, H. A. C., Polymeneas, P., Charalampidis, P. E., Pilinis, C., Wiedensohler, A., Dall'Osto, M., O'Dowd, C., and Pandis, S. N.: Evaluation of a three-dimensional chemical transport model (PMCAMx) in the European domain during the EUCAARI May 2008 campaign, Atmos. Chem. Phys., 11, 10331-10347, https://doi.org/10.5194/acp-11-10331-2011, 2011.

Ghan, S. J., Leung, L. R., and Easter, R. C.: Prediction of cloud droplet number in a general circulation model, J. Geophys. Res. 102, 21777-21794, https://doi.org/10.1029/97JD01810, 1997.

Glassmeier, F.: Constraining susceptibilities of aerosol-cloudprecipitation interactions in warm and cold clouds, $\mathrm{PhD}$ thesis, ETH Zurich, https://doi.org/10.3929/ethz-a-010614474, 2016.

Glassmeier, F. and Lohmann, U.: Constraining precipitation susceptibility of warm, ice- and mixed-phase clouds with microphysical equations:w, J. Atmos. Sci., 73, 5003-5023, https://doi.org/10.1175/JAS-D-16-0008.1, 2016.

Jacobson, M. Z.: Fundamentals of Atmospheric Modeling, Cambridge, 2005. 
Jaecker-Voirol, A. and Mirabel, P.: Heteromolecular nucleation in the sulfuric-acid-water systems, Atmos. Environ., 23, 20532057, 1989.

Kärcher, B. and Lohmann, U.: A parameterization of cirrus cloud formation: Heterogeneous freezing, J. Geophys. Res., 108, 4402, https://doi.org/10.1029/2002JD003220, 2003.

Kazil, J. and Lovejoy, E. R.: A semi-analytical method for calculating rates of new sulfate aerosol formation from the gas phase, Atmos. Chem. Phys., 7, 3447-3459, https://doi.org/10.5194/acp7-3447-2007, 2007.

Kerminen, V.-M. and Wexler, A. S.: Post-fog nucleation of $\mathrm{H}_{2} \mathrm{SO}_{4}-$ $\mathrm{H}_{2} \mathrm{O}$ particles in smog, Atmos. Environ., 28, 2399-2406, 1994.

Knote, C.: Regional scale impacts of changing anthropogenic emissions on aerosols, PhD thesis, ETH Zurich, 2012.

Knote, C. and Brunner, D.: An advanced scheme for wet scavenging and liquid-phase chemistry in a regional online-coupled chemistry transport model, Atmos. Chem. Phys., 13, 1177-1192, https://doi.org/10.5194/acp-13-1177-2013, 2013.

Knote, C., Brunner, D., Vogel, H., Allan, J., Asmi, A., Äijälä, M., Carbone, S., van der Gon, H. D., Jimenez, J. L., Kiendler-Scharr, A., Mohr, C., Poulain, L., Prévôt, A. S. H., Swietlicki, E., and Vogel, B.: Towards an online-coupled chemistry-climate model: evaluation of trace gases and aerosols in COSMO-ART, Geosci. Model Dev., 4, 1077-1102, https://doi.org/10.5194/gmd-4-10772011, 2011.

Köhler, H.: The nucleus in and the growth of hygroscopic droplets, T. Faraday Soc., 32, 1152-1161, 1936.

Kuenen, J., van der Gon, H. D., Visschedijk, A., van der Brugh, H., and van Gijlswijk, R.: MACC European emission inventory for the years 2003-2007, Proj. Rep. TNO-060-UT-2011-00588, TNO, 2011.

Kumar, P., Sokolik, I. N., and Nenes, A.: Measurements of cloud condensation nuclei activity and droplet activation kinetics of fresh unprocessed regional dust samples and minerals, Atmos. Chem. Phys., 11, 3527-3541, https://doi.org/10.5194/acp-113527-2011, 2011.

Lee, L. A., Carslaw, K. S., Pringle, K. J., and Mann, G. W.: Mapping the uncertainty in global CCN using emulation, Atmos. Chem. Phys., 12, 9739-9751, https://doi.org/10.5194/acp12-9739-2012, 2012.

Lee, L. A., Reddington, C. L., and Carslaw, K. S.: On the relationship between aerosol model uncertainty and radiative forcing uncertainty, P. Natl. Acad. Sci. USA, 113, 5820-5827, https://doi.org/10.1073/pnas.1507050113, 2016.

Lin, H. and Leaitch, R.: Development of an In-Cloud Aerosol Activation Parameterization for Climate Modelling, in: WMO Workshop on Measurements of Cloud Properties for Forecasts of Weather and Climate, Mexico City, Mexico, 1997.

Lohmann, U., Lüönd, F., and Mahrt, F.: An introduction to clouds: from microscale to climate, Cambridge University Press, 2016.

Lundgren, K.: Direct Radiative Effects of Sea Salt on the Regional Scale, Ph.D. thesis, KIT, 2012.

Majewski, D., Liermann, D., Prohl, P., Ritter, B., Buchhold, M., Hanisch, T., Paul, G., and Wergen, W.: The operational global icosahedral-hexagonal gridpoint model GME: Description and high-resultion tests, Mon. Weather Rev., 130, 319-338, https://doi.org/10.1175/15200493(2002)130<0319:TOGIHG>2.0.CO;2, 2002.
Mann, G. W., Carslaw, K. S., Reddington, C. L., Pringle, K. J., Schulz, M., Asmi, A., Spracklen, D. V., Ridley, D. A., Woodhouse, M. T., Lee, L. A., Zhang, K., Ghan, S. J., Easter, R. C., Liu, X., Stier, P., Lee, Y. H., Adams, P. J., Tost, H., Lelieveld, J., Bauer, S. E., Tsigaridis, K., van Noije, T. P. C., Strunk, A., Vignati, E., Bellouin, N., Dalvi, M., Johnson, C. E., Bergman, T., Kokkola, H., von Salzen, K., Yu, F., Luo, G., Petzold, A., Heintzenberg, J., Clarke, A., Ogren, J. A., Gras, J., Baltensperger, U., Kaminski, U., Jennings, S. G., O'Dowd, C. D., Harrison, R. M., Beddows, D. C. S., Kulmala, M., Viisanen, Y., Ulevicius, V., Mihalopoulos, N., Zdimal, V., Fiebig, M., Hansson, H.-C., Swietlicki, E., and Henzing, J. S.: Intercomparison and evaluation of global aerosol microphysical properties among AeroCom models of a range of complexity, Atmos. Chem. Phys., 14, 4679-4713, https://doi.org/10.5194/acp-14-4679-2014, 2014.

Marticorena, B., Bergametti, G., Aumont, B., Callot, Y., N'Doumé, C., and Legrand, M.: Modeling the atmospheric dust cycle: 2. Simulation of Saharan dust sources, J. Geophys. Res., 102, 4387 4404, https://doi.org/10.1029/96JD02964, 1997.

McComiskey, A., Feingold, G., Frisch, A. S., Turner, D. D., Miller, M. A., Chiu, J. C., Min, Q., and Ogren, J. A.: An assessment of aerosol-cloud interaction in marine stratus clouds based on surface remote sensing, J. Geophys. Res., 114, D09203, https://doi.org/10.1029/2008JD011006, 2009.

Myhre, G., Shindell, D., Bréon, F.-M., Collins, W., Fuglestvedt, J., Huang, J., Koch, D., Lamarque, J.-F., Lee, D., Mendoza, B., Nakajima, T., Robock, A., Stephens, G., Takemura, T., and Zhang, H.: Anthropogenic and Natural Radiative Forcing, in: Climate Change 2013: The Physical Science Basis. Contribution of Working Group I to IPCC AR5, edited by: Stocker, T. F., Qin, D., Plattner, G.-K., Tignor, M., Allen, S., Boschung, J., Nauels, A., Xia, Y., Bex, V., and Midgley, P., Cambridge, https://doi.org/10.1017/CBO9781107415324, 2013.

Nenes, A. and Seinfeld, J. H.: Parameterization of cloud droplet formation in global models, J. Geophys. Res., 108, 4415, https://doi.org/10.1029/2002JD002911, 2003.

Niemand, M., Möhler, O., Vogel, B., Vogel, H., Hoose, C., Connolly, P., DeMott, P., Skrotzki, J., and Leisner, T.: A particle-surface-area-based parameterization of immersion freezing on desert dust particles, J. Atmos. Sci., 69, 3077-3092, https://doi.org/10.1175/JAS-D-11-0249.1, 2012.

Nightingale, P. D., Malin, G., Law, C. S., Watson, A. J., Liss, P. S., Liddicoat, M. I., Boutin, J., and Upstill-Goddard, R. C.: In situ evaluation of air-sea gas exchange parameterizations using novel conservative and volatile tracers, Global Biogeochem. Cy., 14, 373-387, https://doi.org/10.1029/1999GB900091, 2000.

Noppel, H., Blahak, U., Seifert, A., and Beheng, K. D.: Simulations of a hailstorm and the impact of CCN using an advanced twomoment cloud microphysical scheme, Atmos. Res., 96, 286-301, https://doi.org/10.1016/j.atmosres.2009.09.008, 2010.

Petters, M. D. and Kreidenweis, S. M.: A single parameter representation of hygroscopic growth and cloud condensation nucleus activity, Atmos. Chem. Phys., 7, 1961-1971, https://doi.org/10.5194/acp-7-1961-2007, 2007.

Phillips, V. T. J., DeMott, P. J., and Andronache, C.: An Empirical Parameterization of Heterogeneous Ice Nucleation for Multiple Chemical Species of Aerosol, J. Atmos. Sci., 65, 2757-2783, https://doi.org/10.1175/2007JAS2546.1, 2008. 
Possner, A., Zubler, E., Lohmann, U., and Schär, C.: Realcase simulations of aerosol-cloud interactions in ship tracks over the Bay of Biscay, Atmos. Chem. Phys., 15, 2185-2201, https://doi.org/10.5194/acp-15-2185-2015, 2015.

Pratsinis, S. E.: Simultaneous Nucleation, Condensation, and Coagulation in Aerosol Reactors, Adv. Colloid Interfac., 124, 416427, 1987.

Reinhardt, T. and Seifert, A.: A Three-Category Ice Scheme for the LMK, Tech. rep., Consortium for Small-Scale Modelling, 2006.

Rieger, D., Bangert, M., Kottmeier, C., Vogel, H., and Vogel, B.: Impact of aerosol on post-frontal convective clouds over Germany, Tellus B, 66, 22528, https://doi.org/10.3402/tellusb.v66.22528, 2014.

Riemer, N.: Numerische Simulationen zur Wirkung des Aerosols auf die Troposphärische Chemie und die Sichtweite, $\mathrm{PhD}$ thesis, Universität Karlsruhe (TH), 2002.

Rinke, R.: Parametrisierung des Auswaschens von Aerosolpartikeln durch Niederschlag, PhD thesis, Universität Karlsruhe (TH), 2008.

Seifert, A. and Beheng, K. D.: A two-moment cloud microphysics parameterization for mixed-phase clouds. Part 1: Model description, Meteorol. Atmos. Phys., 92, 45-66, https://doi.org/10.1007/s00703-005-0112-4, 2006.

Seinfeld, J. H. and Pandis, S. N.: Atmospheric Chemistry and Physics, John Wiley \& Sons, 2006.

Slinn, S. A. and Slinn, W. G. N.: Predictions for particle deposition on natural waters, Atmos. Environ., 14, 1013-1016, https://doi.org/10.1016/0004-6981(80)90032-3, 1980.

Solazzo, E.: Operational model evaluation for particulate matter in Europe and North America in the context of AQMEII, Atmos. Environ., 53, 75-92, https://doi.org/10.1016/j.atmosenv.2012.02.045, 2012.

Stanelle, T., Vogel, B., Vogel, H., Bäumer, D., and Kottmeier, C.: Feedback between dust particles and atmospheric processes over West Africa during dust episodes in March 2006 and June 2007, Atmos. Chem. Phys., 10, 10771-10788, https://doi.org/10.5194/acp-10-10771-2010, 2010.

Stevens, B. and Feingold, G.: Untangling aerosol effects on clouds and precipitation in a buffered system, Nature, 461, 607-613, https://doi.org/10.1038/nature08281, 2009.
Stier, P., Feichter, J., Kinne, S., Kloster, S., Vignati, E., Wilson, J., Ganzeveld, L., Tegen, I., Werner, M., Balkanski, Y., Schulz, M., Boucher, O., Minikin, A., and Petzold, A.: The aerosol-climate model ECHAM5-HAM, Atmos. Chem. Phys., 5, 1125-1156, https://doi.org/10.5194/acp-5-1125-2005, 2005.

Ullrich, R., Hoose, C., Möhler, O., Niemand, M., Wagner, R., Höhler, K., Hiranuma, N., Saathoff, H., and Leisner, T.: A new ice nucleation active site parametrization for desert dust and soot, J. Atmos. Sci., 74, 669-717, https://doi.org/10.1175/JAS-D-160074.1, 2017.

van der Gon, H. D., Visschedijk, A., van der Brugh, H., and Dröge, R.: A high resolution European emission data base for the year 2005, Proj. Rep. TNO-034-UT-2010-01895, TNO, 2010.

Vehkamäki, H., Kulmala, M., Napari, I., Lehtinen, K. E. J., Timmreck, C., Noppel, M., and Laaksonen, A.: An improved parameterization for sulfurci acid-water nucleation rates for tropospheric and stratospheric conditions, J. Geophys. Res., 107, 4622, https://doi.org/10.1029/2002JD002184, 2002.

Vignati, E., Wilson, J., and Stier, P.: M7: An efficient size-resolved aerosol microphysics module for large-scale aerosol tranport models, J. Geophys. Res., 109, D22202, https://doi.org/10.1029/2003JD004485, 2004.

Vogel, B., Hoose, C., Vogel, H., and Kottmeier, C.: A model of dust transport applied to the Dead Sea Area, Meteorol. Z., 15, 611624, https://doi.org/10.1127/0941-2948/2006/0168, 2006.

Vogel, B., Vogel, H., Bäumer, D., Bangert, M., Lundgren, K., Rinke, R., and Stanelle, T.: The comprehensive model system COSMOART - Radiative impact of aerosol on the state of the atmosphere on the regional scale, Atmos. Chem. Phys., 9, 8661-8680, https://doi.org/10.5194/acp-9-8661-2009, 2009.

Zhang, K., O’Donnell, D., Kazil, J., Stier, P., Kinne, S., Lohmann, U., Ferrachat, S., Croft, B., Quaas, J., Wan, H., Rast, S., and Feichter, J.: The global aerosol-climate model ECHAM-HAM, version 2: sensitivity to improvements in process representations, Atmos. Chem. Phys., 12, 8911-8949, https://doi.org/10.5194/acp-12-8911-2012, 2012.

Zubler, E. M., Folini, D., Lohmann, U., Lüthi, D., Muhlbauer, A., Pousse-Nottelmann, S., Schär, C., and Wild, M.: Implementation and evaluation of aerosol and cloud microphysics in a regional climate model, J. Geophys. Res., 116, D02211, https://doi.org/10.1029/2010JD014572, 2011. 